\title{
Cancer Chemoprevention by Flavonoids, Dietary Polyphenols and Terpenoids
}

\author{
Imran Sheikh 1(i), VarRuchi Sharma ${ }^{2(\mathbb{D})}$, Hardeep Singh Tuli ${ }^{3(\mathbb{D})}$, Diwakar Aggarwal ${ }^{3(\mathbb{D})}$, Atul \\ Sankhyan 4(iD), Pritesh Vyas ${ }^{1(i)}$, Anil K. Sharma ${ }^{3}$ *:(i), Anupam Bishayee ${ }^{5(D)}$ \\ Department of Biotechnology, Eternal University, Baru Sahib, Sirmour, Himachal Pradesh, India \\ Department of Biotechnology, Sri Guru Gobind Singh College Sector-26, Chandigarh (UT) India-160019 \\ 3 Department of Biotechnology, Maharishi Markandeshwar (Deemed to be University), Mullana-Ambala (Haryana) \\ 4 Department of Dentistry, Swami Devi Dyal Hospital, and Dental College, Panchkula (Haryana) India \\ 5 Lake Erie College of Osteopathic Medicine, 5000 Lakewood Ranch Boulevard, Bradenton, FL 34211 \\ * Correspondence: anibiotech18@gmail.com;
}

Scopus Author ID 55693618000

Received: 2.07.2020; Revised: 28.07.2020; Accepted: 30.07.2020; Published: 2.08.2020

\begin{abstract}
The world population is aging, and cancer is always considered to be one of the major causes of death all over the globe. The advent of recent drug-targeted therapies undoubtedly is going to reduce the incidence of cancer over the coming years. However, the frequency of occurrence of such chronic diseases like cancer would continue to increase. Therefore, the search for a safer and cost-effective treatment is urgently needed. Phytochemicals found in plants, foods, vegetables, tea, etc. have emerged as proven therapeutic compounds modulating signaling pathways involved in cancer. We carried out a structured search of bibliographic databases for peer-reviewed research literature using the keywords: cancer chemoprevention, flavonoids, dietary polyphenols, terpenoids, bioactive, microbiota. Quality of the retrieved papers and characteristic outcomes of the articles included in the study was assessed by employing standard tools and deductive qualitative content analysis methodology. The development of personalized supplements comprising particular phytochemicals has been the key, especially dealing with chronic inflammatory disorders like cancer. Better understanding at the molecular level explains the influence of phytochemicals on human health, which has been extensively covered through this review. Moreover, the wide collection of dietary polyphenols that has significant properties in reference to human health has been highlighted. Furthermore, the etiology of end products of such phytochemicals, especially on the modulation of gut microbiota and the host-microbial interactions thereof, need to be properly understood. The present study summarizes the chemoprevention and treatment of cancer using the bioactive components, including flavonoids, dietary polyphenols, and terpenoids. Likewise, the effect of dietary polyphenols on the human gut microbiota has been realized more recently. However, more research is needed in this field, especially focused on the communications, interlinks between the gut microbiota and polyphenols with the precise mechanism of action.
\end{abstract}

Keywords: Cancer chemoprevention; Flavonoids; Dietary Polyphenols; Terpenoids; Bioactive; Microbiota.

(C) 2020 by the authors. This article is an open-access article distributed under the terms and conditions of the Creative Commons Attribution (CC BY) license (https://creativecommons.org/licenses/by/4.0/).

\section{Introduction}

Cancer has been listed worldwide as a significant cause of mortality amid various developments in modern medicines. The development of more operational chemoprevention measures and methods of treatment are needed for the enhancement of recovery rates of cancer patients. As cancer is largely a preventable disease; thus, prevention is generally considered to 
avert the disease. Dietary phytochemicals have a rich history of being used effectively for cancer treatment as these are considered to be most safe in terms of lower toxicity levels and the ease of availability.

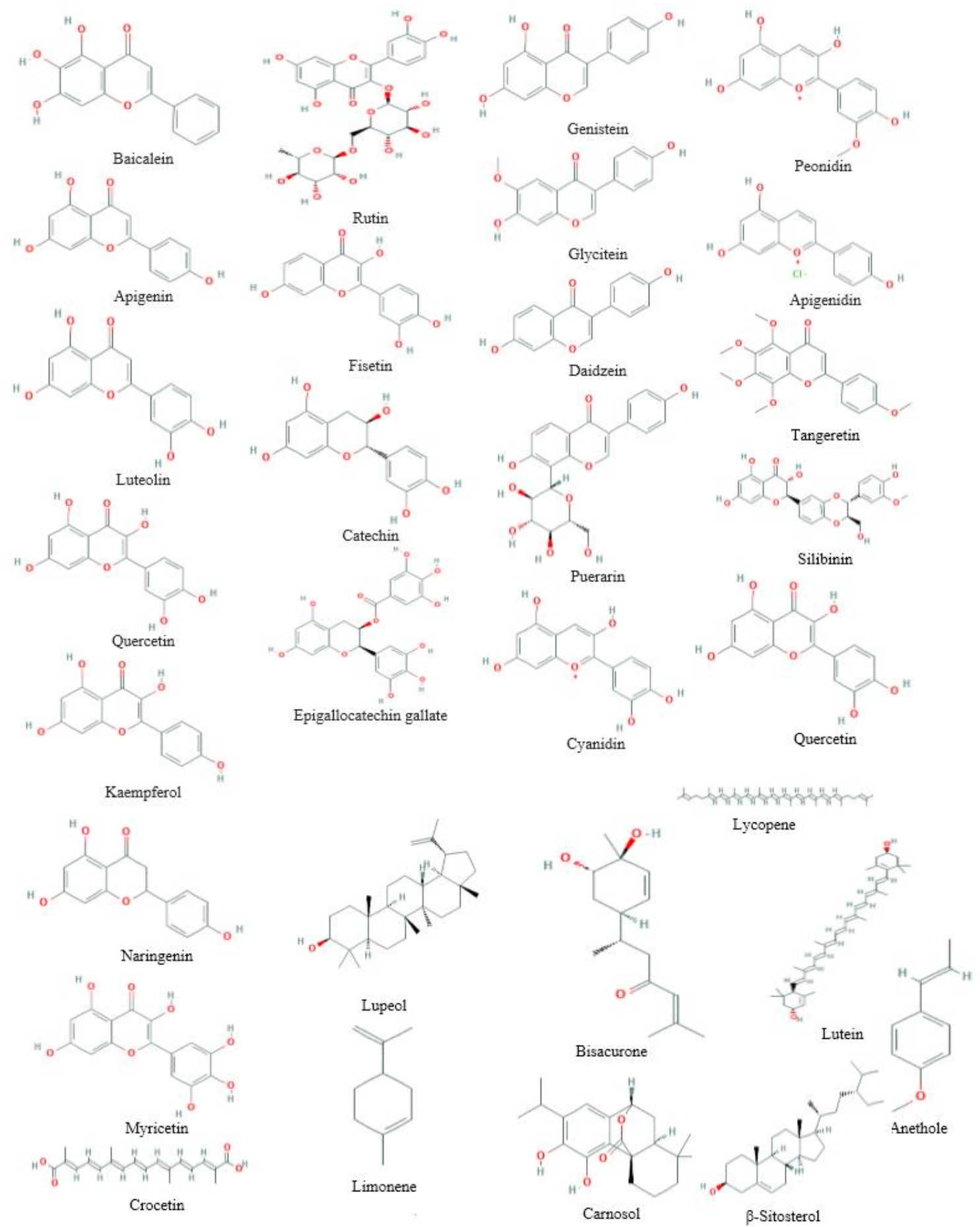

Figure 1. Depiction of categories of major flavonoids and other dietary polyphenols and terpenoids along with their chemical structures.

It has been proposed in several studies that vegetables and fruit diets were often associated with a lower risk of cancer. There have been studies of successful phytochemicals disrupting signaling pathways leading to cancer. Hence, cancer chemoprevention and bioactivities of natural phytochemicals are of wide concern to the medical and scientific fraternity. A wide-array of putative chemo-preventive compounds are under investigation. Sporn et al. [1] first introduced the term chemoprevention by using either natural or synthetic 
agents. A new definition of chemoprevention has emerged recently, describing them as the compounds with the potential of suppressing molecular pathways that are leading to cancer development and metastasis. Different food habits in various countries have become more accountable for lower or higher incidences of cancer progression in their ethnic groups, suggestive of a putative relationship between the food components and carcinogenesis [2]. For instance, in the Asian population, lower prevalence of cancers such as breast, prostate, and gastrointestinal tract cancers, have been reported. The compounds with chemo-preventive activities mainly consist of (i) polyphenols, such as green tea, quercetin extracted from onions, genistein, a soy flavonoid, resveratrol extracted from grapes or curcumin, etc. (ii) polyunsaturated fatty acids (n-3 PUFAs), (iii) carotenoids ( $\beta$-carotene and lycopene or lutein), (iv) vitamins (Vitamin D, E, C/ folic acid, etc.), (v) minerals such as Se, Zinc, Calcium, (vi) essential ingredients, dietary fibers, etc. The diets in humans have an essential role in controlling or preventing various diseases [3]. The regular diet checkups and routine control over diet have a positive impact on any disease in humans, including cancer. Hippocrates has suggested, "Let food be thy medicine and medicine be thy food". Diet in our body acts in both ways, either pro-healthy or can also act as harmful depending on the ingredients $[2,4]$. Some dietary substances were recorded as carcinogens that initiate or their gradual stimulation leads to tumor growth in the body [5,6]. Food, however, contains large-scale bioactive compounds that are useful to humans. Numerous studies in the literature have shown that there is a negative association between sufficient vegetable and fruit consumption or intake versus cancer. A wellbalanced diet must be containing macronutrients such as omega-3 fatty acids and fibers, selenium, calcium, vitamin D and E, folates, etc., along with phytochemicals that are rich in cancer prevention properties viz. polyphenols, flavonoids, carotenoids (Figure 1 and Figure 2). Therefore, as evidenced through various researches, phytochemicals, or dietary agents have a profound role in cancer prevention and cure $[7,8]$.

\section{Flavonoids}

A variety of edible items like fruits, vegetables, floral plants, chocolate, tea/leaves, wine products, and other plant sources are rich sources of dietary flavonoids $[9,10]$. Flavonoids can be further divisible into subfamilies, which may include flavones, flavonols, isoflavones, flavanones, and flavanonols, etc. [11]. Figure 1 clearly elucidates the categories of major flavonoids and other major polyphenols relevant to the present review, along with their chemical structures $[7,12]$.

However, all the family members of this family share common basic chemical structural composition of having two benzene rings, which are connected by a three-carbon bridge, and forms a heterocyclic structure (C6-C3-C6) [13]. In terms of safety, flavonoid compounds have been reported not to exceed the toxicity limit of $140 \mathrm{~g} /$ day. Moreover, they do not exhibit any noteworthy adverse effects as well [14]. In reference to the pharmacological effects of flavonoid compounds, they have broad-spectrum properties, including strong antioxidant properties, anti-inflammatory effects, cardio-protective, hepatoprotective, antimicrobial, and anticancer activities $[15,16]$. Yet, isolation and purification of flavonoids is a difficult process. Epidemiological and clinical laboratory researches have shown that dietary flavonoid consumption decreases the risk of certain cancers [17]. Flavonoids have shown antiproliferative effects in variety of cancers, including (a) silymarin, (b) genistein, (c) quercetin, (d) daidzein, (e) luteolin, (f) kaempferol, (g) apigenin, (h) epigallocatechin 3-gallate etc. [18]. 
These compounds have anti-tumorigenic effects against prostate, colorectal, breast, thyroid, lung, and ovarian cancers.

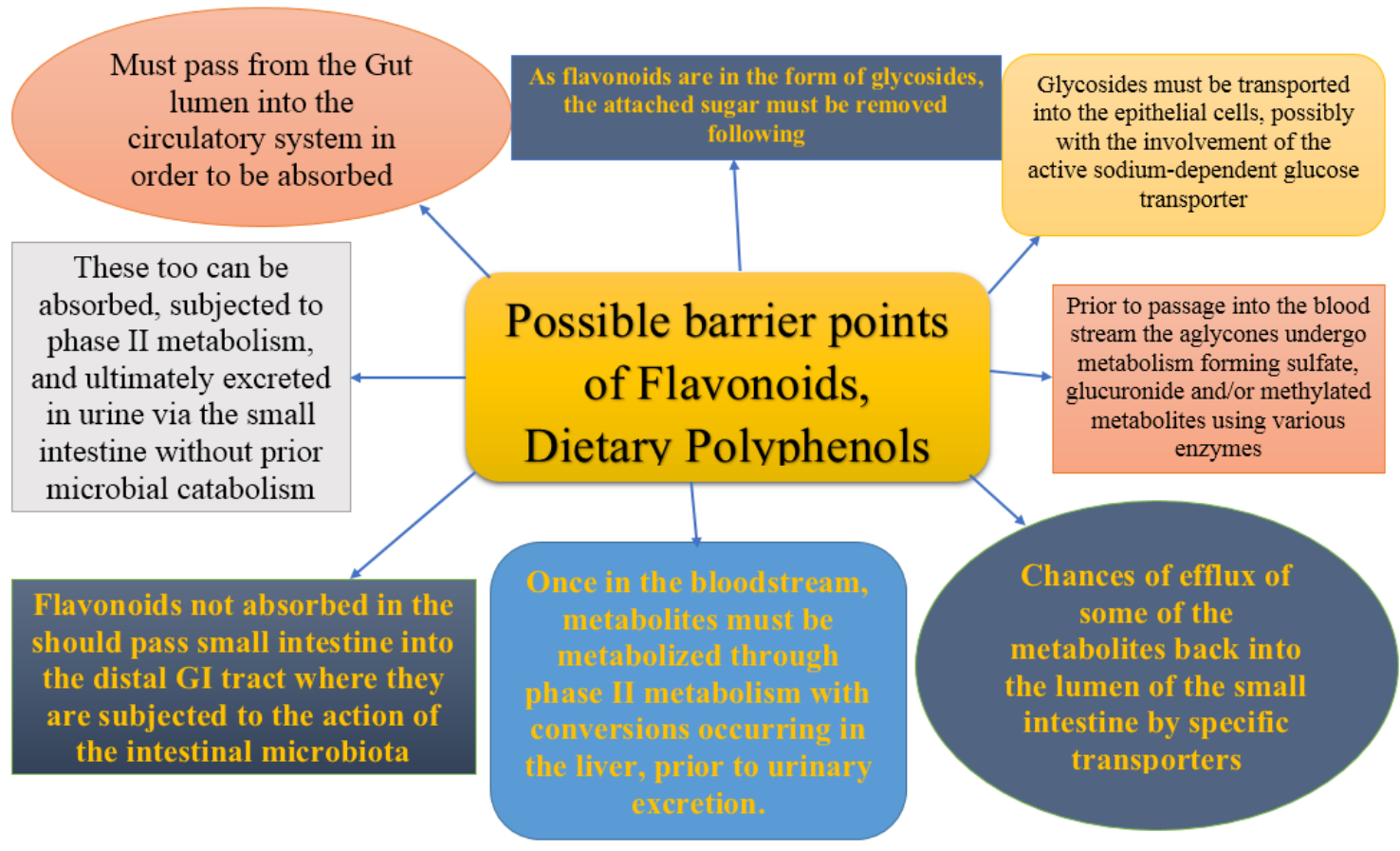

Figure 2. Possible challenges associated with pharmacokinetics and absorption of flavonoids, dietary polyphenols, and terpenoids.

There are some of the mediating factors that facilitate the chemopreventive efficacy of flavonoids, including inhibition of development of new cancer cells, prevention of carcinogens to reach to respective activation sites, reduction in the toxicity levels of particular compounds by the inhibition of their metabolism [19]. The molecular mechanisms by which flavonoids have shown anticancer include (1) stimulation of apoptosis [20] (2) cell cycle arrest at G1 or G2/ M phase, i.e., cycline-dependent kinases (CDKs) may inhibit cell cycle regulators (3) inhibition of enzyme metabolism (mainly cytochrome P450), which further inhibits the carcinogenic compound activation (4) reactive oxygen species (ROS) inhibition by activating phase II metabolizing enzymes and (5) vascular endothelial growth factor (VEGF) inhibition along with basic fibroblast growth factor (bFGF) guided angiogenesis [21]. Numerous flavonoids were recorded to inhibit multidrug resistance responsible for cancer relapse and chemotherapy failure [22]. Some of the flavonoids exhibit specific mechanisms of action that are not articulated as the characteristic of the family of flavonoids. Such flavonoids are genistein, isoflavones, and diadzein, which have been reported to suppress cancer growth as well as proliferation [23,24]. They have shown some structural similarity with estrogen, genistein, and diadzein, which are described to have strong efficacy against breast cancer $[25,26]$. Another flavonoid, silybin, has also been shown to have antioxidant and numerous pharmacological anti-cancer properties viz. inhibition of other factors including (1) Nuclearfactor kappa-B (NF-T,B) mediated tumor-necrosis-factor (TNF) stimulation. Alpha (I $\alpha$ ) to NFŢB (active form) was seen to inhibit phosphorylation and proteolytic decay of the kappa light polypeptide enhancer nuclear factor in B-cell receptor [27] (2) tyrosine kinases [28] (3) androgen receptors [29] and (4) the epithelial to mesenchymal transition through embryonic pathways [30,31]. Quercetin, another flavonoid that also exhibits antioxidant properties, has been found to exist in some dietary substances such as onions, berries, apples, red wine, etc. 
[9,32]. Quercetin has been shown to display anticancer efficiency in colon cancer and neurogliomas as well. The efficacy of this flavonoid compound is attributed to the activation of signaling pathways for autophagy and mitogen-activated protein kinases (MAPK or extracellular kinases [33]) [34,35]. Several studies have been published on the prospective role of flavonoids in cancer treatment and prevention [10]. A variety of flavonoids and their essential formulations are available in dietary supplements such as milk thistle and red clover extracts [36]. However, none of the flavonoids mentioned here were authorized for clinical use. With numerous pre-clinical studies, it has been proposed that flavonoids have substantial anticancer effects [Table 1], however, there are many hindrances and challenges in flavonoids production as a clinically authorized product and about their role in significantly reducing the risk of cancer.

Table 1. Classification and sources of dietary phytochemicals possessing antitumor activities.

\begin{tabular}{|c|c|c|c|c|}
\hline $\begin{array}{l}\text { Sr. } \\
\text { No. }\end{array}$ & $\begin{array}{l}\text { Functional } \\
\text { component }\end{array}$ & Dietary source & $\begin{array}{l}\text { Functional Property } \\
\text { Action Potential }\end{array}$ & Ref. \\
\hline A & $\begin{array}{l}\text { Polyphenols } \\
\text { Flavonoids } \\
\end{array}$ & & & \\
\hline 1 & Apigenin & Parsley and celery & $\begin{array}{l}\text { anti-inflammatory, antioxidant, } \\
\text { antibacterial and antiviral activities }\end{array}$ & [37] \\
\hline 2 & Butein & $\begin{array}{l}\text { Indian cashew } \\
\text { (Semecarpus anacardium) }\end{array}$ & $\begin{array}{l}\text { antioxidative, Inhibition of aldose } \\
\text { reductase and advanced glycation end } \\
\text { products inhibitory effects, } \\
\text { inhibits TNF-dependent NF-kB } \\
\text { degradation and phosphorylation }\end{array}$ & {$[26,38-40]$} \\
\hline 3 & Catechingallate & Green tea & 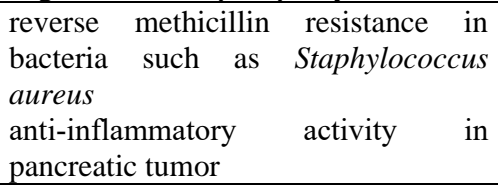 & [41] \\
\hline 4 & Cyanidin & $\begin{array}{l}\text { Wild } \quad \text { blueberry } \\
\text { (Vaccinium myrtiillus) }\end{array}$ & $\begin{array}{l}\text { probable sirtuin } 6 \text { (sirt6) activator } \\
\text { acts as a natural inhibitor of intestinal } \\
\text { lipid digestion and absorption }\end{array}$ & {$[42]$} \\
\hline 5 & Daidzein & Soybean & $\begin{array}{l}\text { Inhibitory effects against prostate } \\
\text { cancer, bladder cancer, breast cancer, } \\
\text { diabetes }\end{array}$ & {$[43,44]$} \\
\hline 6 & Delphinidin & $\begin{array}{l}\text { Cranberry, strawberry, } \\
\text { Pomegranate }\end{array}$ & $\begin{array}{l}\text { antioxidant and anti-inflammatory } \\
\text { properties }\end{array}$ & {$[45]$} \\
\hline 7 & Epicatechin gallate & Green tea & $\begin{array}{l}\text { antioxidant, tyrosinase inhibitory } \\
\text { activity, beneficial in preventing } \\
\text { metabolic syndrome }\end{array}$ & {$[46,47]$} \\
\hline 8 & Fisetin & Strawberry, apple & $\begin{array}{l}\text { antioxidant, anti-inflammatory } \\
\text { activity, causes reduction in the age- } \\
\text { related decline in brain function, } \\
\text { activates key neurotrophic factor } \\
\text { signaling pathways }\end{array}$ & {$[48,49]$} \\
\hline 9 & Genistein & Soybean & $\begin{array}{l}\text { antineoplastic agent, prostate cancer, } \\
\text { bladder cancer, and breast cancer }\end{array}$ & {$[50,51]$} \\
\hline 10 & Isoliquiritigenin & $\begin{array}{l}\text { Licorice } \quad \text { (Glycyrrhiza } \\
\text { glabra })\end{array}$ & $\begin{array}{l}\text { anti-inflammatory, antiviral, } \\
\text { antidiabetic, antispasmodic, antitumor } \\
\text { activities, anti-proliferative, a } \\
\text { supplement to ease the menopause } \\
\text { symptoms, an anti-tumor agent in the } \\
\text { pituitary gland. }\end{array}$ & {$[52,53]$} \\
\hline 11 & Kaempferol & Tea, broccoli, grapes & $\begin{array}{l}\text { antioxidant, prevent arteriosclerosis, } \\
\text { protects against various oxidative } \\
\text { stresses, protects against inflammatory } \\
\text { age-related chronic disorders. }\end{array}$ & {$[54]$} \\
\hline 12 & Luteolin & $\begin{array}{l}\text { Licorice } \\
\text { (Glycyrrhizaglabra) }\end{array}$ & $\begin{array}{l}\text { neuroprotective, antioxidant, pro- } \\
\text { oxidant activity, estrogenic, anti- } \\
\text { estrogenic activity, anti-inflammatory, } \\
\text { anti-cancerous. }\end{array}$ & {$[55,56]$} \\
\hline 13 & Xanthohumol & $\begin{array}{l}\text { Beer (from Humulus } \\
\text { lupulus) }\end{array}$ & $\begin{array}{l}\text { anti-inflammatory, } \\
\text { hypoglycemic } \\
\text { anticancerous, fights } \text { with oxidative }\end{array}$ & [57-59] \\
\hline
\end{tabular}




\begin{tabular}{|c|c|c|c|c|}
\hline & & & $\begin{array}{l}\text { stress, regulate fat metabolism and } \\
\text { storage, cholesterol modulation. }\end{array}$ & \\
\hline 14 & Tangeretin & Citrus fruits & $\begin{array}{l}\text { lowering of cholesterol levels, anti- } \\
\text { tumor, and neuroprotective action. }\end{array}$ & {$[60,61]$} \\
\hline 15 & Silibinin & $\begin{array}{l}\text { Milk thistle (Silybum } \\
\text { marianum) }\end{array}$ & $\begin{array}{l}\text { shows antioxidant, antineoplastic and } \\
\text { hepatoprotective activities }\end{array}$ & {$[62-64]$} \\
\hline 16 & Quercetin & Onion, apple, broccoli & $\begin{array}{l}\text { reduces inflammation, blood pressure, } \\
\text { and blood sugar levels }\end{array}$ & {$[65,66]$} \\
\hline 17 & Naringenin & Grapes, citrus & $\begin{array}{l}\text { anti-dyslipidemic, anti-obesity and } \\
\text { anti-diabetic and antifibrotic } \\
\text { properties. }\end{array}$ & {$[67,68]$} \\
\hline 18 & Myricetin & Grapes, onion, tea & $\begin{array}{l}\text { antioxidant, anticarcinogenic, anti- } \\
\text { mutagenic, antiviral, antithrombotic, } \\
\text { anti-inflammatory }\end{array}$ & [69] \\
\hline \multirow[t]{2}{*}{$\mathrm{B}$} & Terpenoids & & & \\
\hline & Carotenoids & & & \\
\hline 1 & Crocetin & Saffron & antioxidant and anticancer properties & [70-72] \\
\hline 2 & Lutein & Spinach & antioxidant properties & {$[73,74]$} \\
\hline 3 & Lycopene & $\begin{array}{l}\text { Tomato, Watermelon, red } \\
\text { grapes }\end{array}$ & $\begin{array}{l}\text { helps in improving heart health, } \\
\text { lowering the risk of certain types of } \\
\text { cancer }\end{array}$ & [75] \\
\hline 4 & Lupeol & Mango, strawberry & anti-inflammatory, anti-cancer effects & {$[76]$} \\
\hline 5 & Limonene & $\begin{array}{l}\text { Citrus fruits, cherries, } \\
\text { grapes }\end{array}$ & $\begin{array}{l}\text { helpful against obesity, cancer, and } \\
\text { bronchitis }\end{array}$ & {$[77]$} \\
\hline 6 & Anethole & $\begin{array}{l}\text { Sweet fennel (Foeniculum } \\
\text { vulgare) }\end{array}$ & $\begin{array}{l}\text { used to flavor various foods and } \\
\text { cosmetic products. }\end{array}$ & [78] \\
\hline 7 & Bisacurone & $\begin{array}{l}\text { Turmeric } \quad \text { (Curcuma } \\
\text { longa) }\end{array}$ & $\begin{array}{l}\text { anti-inflammatory, anti-oxidant, and } \\
\text { anti-metastatic properties. }\end{array}$ & {$[79,80]$} \\
\hline 8 & Carnosol & Rosemary & $\begin{array}{l}\text { anti-cancer and anti-Inflammatory in } \\
\text { nature. }\end{array}$ & {$[81,82]$} \\
\hline $\mathrm{C}$ & Phytosterols & & & \\
\hline 1 & $\beta$-Sitosterol & Nuts, grains, seeds & $\begin{array}{l}\text { help to reduce cholesterol levels, } \\
\text { effective against enlarged prostate, } \\
\text { anticancer effects }\end{array}$ & {$[83,84]$} \\
\hline
\end{tabular}

\subsection{Isolation and purification of flavonoids.}

Low concentrations of the desired compound (from micro to milligrams per $\mathrm{kg}$ of plant masses) have been a major challenge in the extraction of flavonoids from the concerned plant sources [85]. The continuous removal of these anticancer compounds may lead to the elimination of the plant source, disrupting all plant communities and ecosystems. Secondary metabolites, minerals, vitamins, and fibers have all been derived from plants itself [36]. Thus, the complete plant ingredients could be responsible for the beneficial effects of anticancer products. However, the ability of flavonoids to form complexes with other compounds makes it more difficult to comprehend and identify the key molecule responsible for pharmacological effects. Combinatorial methods may be used to separate different compounds, including solvent extraction, column chromatography, medium-pressure liquid chromatography, vacuum column chromatography, and prepared high-performance liquid chromatography (HPLC) [8688]. The implementation of such measures is a time-consuming process that may have an association with high costs [89]. Similarly, even with the involvement of these complex techniques, still, the yield of the isolated compound remains even less than $1 \mathrm{~g}$. Another reason attributed to low yield is the complex biosynthetic pathway of flavonoids resulting in varied flavonoids composition at different stages of plant development, even under changed environmental conditions [90, 91]. Different flavonoid compositions also affect the predictability of flavonoid yields at the time of extractions, though the data after each extraction has not been consistent [92]. Some disadvantages include labile flavonoid extraction in these compounds, which exposes them to exceptional rates of degradation or alterations in their chemical structures and subsequent loss of function during purification. Thus, flavonoids 
harvested from plant products using existing techniques, have proven to be costs associated with low yields and cumbersome as well.

\subsection{Challenges associated with Pharmacokinetics (PK).}

Flavonoids usually have an inappropriate PK profile viz. ADMET profile [93] with lower solubility, poor oral absorption, and faster liver metabolism through phase I and II enzymes [94,95]. These flavonoids are usually consumed with supplementary food constituents. As a result, there is a precipitation of flavonoid compounds that limit their levels of absorption as well as bioavailability [96]. Flavonoids can also undergo metabolism via deglycosylation before they get absorbed in the small intestine [97]. They may act as substrates for sulfation, O-methylation, and glucuronidation in vivo resulting in the rapid excretion in urine $[98,99]$. Besides, the unabsorbed part can reach the colon, which further can undergo degradation by the intestinal micro-flora either through ring fission [100], reduction [101], or hydrolysis. For example, in the case of quercetin taken orally, only a 20-30\% quantity is bioavailable. In the case of silybin, its anti-cancerous properties are restricted by its low oral absorption and low bioavailability [102]. Complete degradation of flavan-3-ols has been reported to occur after its exposure to simulated intestinal secretions after 8 hours of time duration [103,104]. These above-mentioned PK liabilities display substantial barriers to the clinical developments of flavonoids [105] [Figure 2]. Moreover, the higher dosages of flavonoids ingested may result in proliferative and inflammatory responses [106]. Furthermore, due to their numerous in vivo interactions, flavonoids could affect bioavailability and efficacy of different drugs viz. certain flavonoids may affect cytochrome 450 (CYPs) [107], conjugation enzymes, $\alpha$-amylase, $\alpha$-glucosidases, bovine hemoglobin, multidrug resistance transporters (Morris and Zhang, 2006), colonic microflora and plasma proteins [108].

\subsection{Interactions with $A B C$ drug transporters.}

The ATP-binding cassette (ABC) superfamily consists of some essential members serving as mediators between PK alterations (i.e., ADMET) and multidrug resistance (MDR) to various antineoplastic drugs, along with flavonoids, serving as substrates for these transporters [109-112]. The transporters, along with two transmembrane domains, are located on the cell membranes that recognize diverse compounds and form channels within the membrane in order to efflux these compounds [113,114]. ABC transporters are though omnipresent in our body but are present in higher densities in barrier-functioning tissues such as gastrointestinal tract, reproductive organs, kidney, liver, and blood-brain barriers [115]. $\mathrm{ABC}$ transporters have been widely known to have a role in controlling drug absorption, distribution, and excretion, which can reduce bioavailability and efficacy [116]. Several studies have been performed to explore possible interactions between flavonoids and $\mathrm{ABC}$ transporters. Flavonoids such as flavones (e.g., apigenin and chrysin), isoflavones (e.g., biochanin A and genistein), flavonols (kaempferol) and flavanones (naringenin) are known to inhibit the efflux function of ABC carriers such as ATP binding cassette subfamily B member 1 (ABCB1) and ABCG2 [117]. Flavonoids inhibiting ABC transporters could have potential advantages and disadvantages as well [118]. ABC inhibition of transporters may increase the bioavailability of certain poorly available drugs, potentially enhancing the absorption, distribution, bioavailability, and effectiveness of other drugs, including antineoplastics. This can be used to resolve multidrug resistance (MDR) and chemotherapy failure [117]. For 
example, isoflavonoids may induce apoptosis in multidrug-resistant P388 leukemia cells and further overcome resistance mechanisms [119]. Epigallocatechin-3-gallate, when administered through intragastric gavage at a dosage of $10 \mathrm{mg} / \mathrm{kg}$ body weight as a suspension in $0.2 \%$ agar (once daily for 10 days), was reported to significantly decrease the expression of P-gp, resulting in increased atorvastatin and verapamil plasma levels in male Wistar rats which further potentiate their pharmacological effects [120-123]. However, inhibition of ABC transporters by the flavonoids may potentiate the toxicity of certain $\mathrm{ABC}$ substrates and cause unintended adverse or toxic effects of certain antimicrobials, immuno-suppressants, cardiovascular, and chemotherapeutic drugs [124].

\subsection{Interactions of intestinal microflora.}

Depending on the compound, a substantial proportion can hit the colon after oral administration of flavonoids and undergo microflora degradation and enterohepatic circulation [125]. Colonic microflora is considered to be the most abundant human microbiome [126,127]. These microorganisms were shown to bio-transform other drugs into metabolites, altering their effectiveness and toxicity [128]. They not only also act as pathogen barriers but also protect against harmful xenobiotics. Colonic microflora may also decrease cholesterol absorption and improves intestinal mucus production $[129,130]$. The role of colonic microflora in the absorption, metabolism, and bioavailability of flavonoids is yet to be established [131]. Unabsorbed flavonoids can be bio-transformed into small phenolic compounds having similar effects but with improved bioavailability in comparison to parent compounds [132]. By comparison, through the enzymes glucuronidase and sulphatase, colonic microflora can extensively metabolize flavonoids, producing metabolites that are predominantly inert and are rapidly excreted polar compounds [133]. Some flavonoids (e.g., apigenin, genistein, naringenin, and kaempferol) are more vulnerable than others to microfloral degradation, resulting in a lower bioavailability [134]. Recent research has shown that certain flavonoids can inhibit intestinal microflora and the associated processes of fermentation [135]. Ellagitannins and flavan-3-ols from raspberry extracts were shown to inhibit ellagitannins and $\beta$-galactosidase [136]. In addition, antibiotic usage should be controlled when used along with flavonoids because they can alter gut microflora composition that ultimately affects flavonoid bioavailability [137]. The wide range of flavonoid structures and the microbial composition of the gastrointestinal tract, thus reduce the predictability of the types of interactions that occur, as well as the effects and permeability of the resulting compounds.

\subsection{Approaches to overcome pharmacokinetic/pharmacodynamics $(P K / P D)$ and other} barriers.

There are several approaches to strengthen and resolve the therapeutic applications of dietary flavonoids.

2.5.1 Improving purification and isolation yields.

Current conventional isolation and purification methods usually result in lower flavonoid extraction yield, while having higher extraction costs. Nonetheless, optimizing conditions in these conventional extraction methods will certainly increase the flavonoid yield. Response Surface Methodology (RSM) was used to optimize flavonoid extraction from herbal medicines like Citrus aurantium L., with ethanol [138]. RSM is an experimental designed 
quantitative and statistical method [139] that had significantly increased the yield of Chinese Huangqi flavonoids when the extraction parameters were optimized having an ethanol concentration of $52.98 \%$, extraction time of $2.12 \mathrm{hrs}$, extraction temperature of $62.46^{\circ} \mathrm{C}$ while the liquid-solid ratio of 35.23 [138]. However, these optimization parameters are required for each flavonoid plant source, which is again a laborious and time-consuming process. Therefore original concrete methods need to be used to minimize the cost and degradation of extracted flavonoids from their natural sources [140]. The use of high-speed, counter-current chromatography with lower costs and higher yields, have been tried in the past success as an innovative approach [141]. Nano-harvesting, using nanoparticles in order to remove flavonoids from their source, is another innovative approach adopted previously [142]. This technique avoids the use of organic solvents, allowing continuous processing of flavonoids and opening up a new age of natural product extraction methods [143]. The ultrasonic extraction method employed previously was aimed at enhancing extraction performance and minimizing the extraction time $[144,145]$. However, the extraction of other compounds from the same plant source will seriously harm plant ecological communities. Therefore, industrial-scale microbial production of plant-natural products like flavonoids is actually an attractive option [146]. This strategy will preserve environmental resources and use low-energy and waste emission-related economic stocks.

\subsubsection{Resolution of pharmacokinetics issues of flavonoids.}

A variety of methods or solutions persist in order to address factors that lower flavonoids bioavailability. For example, flavonoid formulation can lead to increased bioavailability compared to flavonoid alone or other types of glycosides [147]. Such derivatives are substrates for other intestinal carriers that improve absorption [148]. Quercetin-4'-Oglucoside administration resulted in plasma levels five times greater than quercetin-3Orutinoside. Therefore, transforming quercetin glycosides into glucosides can be considered as an approach to improve flavonoid bioavailability [147]. The use of bio-enhancers can be employed to incorporate piperine, an amide alkaloid extracted from Piperaceae plants [149]. Piperine greatly inhibits the conjugation of various phase II UDP-glucuronosyltransferase enzymes, such as quercetin [150] and epigallocatechin-3-gallate [151], reducing metabolism while increasing bioavailability [150]. Also, the ability of intestinal microflora modulators can be considered to enhance flavonoid bioavailability [152]. One of the most effective techniques for optimizing PK/PD parameters is to optimize the flavonoid structure in order to generate original derivatives. To retain their desired effects, these compounds must contain the essential parent pharmacophore. Methyl and hyro-silybin derivatives are reported to be ten-fold stronger than silybin [153]. Introducing hydrophobic functional groups (e.g., ethyl substitution) to the quercetin hydroxyl $(\mathrm{OH})$ groups significantly enhance their stability by preventing hydroxyl group oxidative degradation [154]. It has also been shown that blocking other quercetin groups (e.g., C3 hydroxyl and C7 hydroxyl groups) by adding lipophilic moiety pivaloxymethyl $(\mathrm{POM})$, increases the solubility, stability (half-life increased from $10 \mathrm{~h}$ for quercetin to over 72 $\mathrm{h}$ for its quercetin-POM conjugates at $\mathrm{pH}$ 7.4) and efficacy by preventing chemical and metabolic hydrolysis [155]. Emulsified flavonoids are released gradually over time, allowing for a higher absorption surface region, eventually increasing absorption and bioavailability after oral administration [156]. Another method is the advanced delivery system of nanocrystal, self-stabilized Pickering emulsion, which was effectively used for the distribution of certain flavonoids like silybin [157]. Formulating flavonoids as povidone-mixed microparticles 
were shown to substantially improve their release and PK profile [158]. Quercetin encapsulation in Zein nanoparticles has been shown to increase protective efficacy in a mouse endotoxemia model [159]. Protein-complexed flavonoid was shown to improve in vitro stability [160]. Several studies show that flavonoids can be used to improve chemical stability as well [161].

\subsection{Dietary polyphenols.}

Polyphenols are a significant class of phytochemicals. These plant-derived polyphenols are instrumental in shielding plants from photosynthetic stress, reactive oxygen species (ROS), and herbivore consumption. Also, polyphenols are the most abundant compounds present in human food, including flavonoids and phenolic acids. There is a growing understanding that lower cancer incidence may be due to the use of various nutrients, particularly polyphenol-rich diets. In recent years, a systematic study of polyphenolic compounds chemo-preventive ability has clearly established their health benefits, including anti-cancer properties [Table 1]. A large number of studies in cultivated cells, animal models, and human clinical trials demonstrated a protective effect of dietary polyphenols against different cancers [162,163]. Over 8,000 different polyphenols exist and can be classified into ten general categories based on their chemical structure [164]. Phenolic acids, flavonoids, stilbenes, and lignans are the most common polyphenols in food worldwide. EGCG (green tea), curcumin (curry), and resveratrol (grapes and berries) are among the most widely studied and feasible cancer chemo-preventive polyphenols. Chemo-preventive effectiveness involves their ability to suppress or reverse cancer by acting on intracellular signaling network molecules involved in cancer initiation and/or promotion, or their ability to promote cancer arrest or reversal [165]. Polyphenolic compounds can also induce apoptosis in cancer cells by modulating several main elements in apoptosis-linked cell transduction pathways (caspases, $b c l$-2 genes) [166].

Table 2. Association between flavonoids or foods rich in phenolic compounds and cancer prevention.

\begin{tabular}{l|l|l|l} 
& Effects & Sample size & Ref. \\
\hline Flavonoids & Decrease cancer risk at all sites & 9959 Men & {$[167]$} \\
\hline $\begin{array}{l}\text { Quercetin, Onions, } \\
\text { white grapes }\end{array}$ & Decrease cancer risk in the oral cavity, pharynx, larynx, & 540 People & {$[168]$} \\
\hline Quercetin & Decrease the incidence of lung cancer & 582 People & {$[169]$} \\
\hline $\begin{array}{l}\text { Quercetin, } \\
\text { kaempferol }\end{array}$ & Decrease the risk of gastric cancer & 10054 Men & {$[170]$} \\
\hline Catechins & Decrease the incidence of rectal cancer & 354 People & {$[171]$} \\
\hline Tea & Decrease the risk of colon cancer & 34651 Women & {$[172]$} \\
\hline Green tea & Reduced risk of cancer in different organs & 12170 People & {$[173]$} \\
\hline & Reduced risk of breast cancer recurrence and metastasis & 4552 People & {$[174]$} \\
\hline Black tea & No association with gastric cancer & $\begin{array}{l}11902 \text { Men and 14409 } \\
\text { Women }\end{array}$ & {$[175]$} \\
\hline & $\begin{array}{l}\text { No association with risk of colorectal, stomach, lung and } \\
\text { breast cancer }\end{array}$ & $\begin{array}{l}58279 \text { Men and } 62573 \\
\text { Women }\end{array}$ & {$[177]$} \\
\hline Soya & Decreased risk of lung cancer & 999 Men & {$[178]$} \\
\hline & Decreased risk of breast cancer & 34759 Women & {$[179]$}
\end{tabular}

\section{Tea}

Tea (Camellia sinensis) has been the most popular drink consumed by over two-thirds of the water-side population worldwide. The Chinese used tea as a drink as early as $3000 \mathrm{BC}$ to as late as the sixth century. This tea simply comprised of two or three leaves, ending apical buds of $C$. Sinensis, C. asamica, and other southern varieties. Several million tons of dried tea 
is produced annually of which about $20 \%$ is the green tea, mostly consumed in Asian countries where tea is a common drink, while about $78 \%$ is the black tea, mostly consumed in Western nations and some Asian countries. Around $2 \%$ of dried tea is oolong tea, mainly produced and consumed in Southeast China. Black tea is produced by crushing leaves, resulting in oxidasedependent polyphenol polymerization leading to the production of theaflavins, arubigins, and other oligomers in a fermentation method. Theaflavins, like theaflavin, theaflavin-3-O-gallate, theaflavin-3/-Ogallate, and theaflavin-3-3/-O-digallate, have dihydroxy or trihydroxy substitution benzotropolone rings, giving the characteristic color and taste of black tea. This tea is partially fermented with monomeric catechins, theaflavins, and arubigins. Green tea is produced at high temperatures by steaming or drying fresh tea leaves. Green tea primarily consists of polyphenols, flavandiols, flavonoids, and phenolic acids, adding up to $30 \%$ of dry weight. Most polyphenols, also called catechins, caffeine, theobromine, and theophylline, are common alkaloids that account for around $4 \%$ of dry weight [180]. Polyphenols are present at $30-35 \%$ in dry tea leaves, which ultimately determine the consistency of the drink. Tea polyphenols are known to exhibit anti-carcinogenesis effects through a variety of mechanisms that vary for different types of cancers and for the same cancer in different populations. Several labs have reported inhibitory effects of tea polyphenols on tumor production and growth, primarily due to antioxidant and possible anti-proliferative effects of polyphenolic compounds present in green and black tea. These polyphenolics can inhibit carcinogenesis by preventing the endogenous formation of $\mathrm{N}$-nitroso compounds, suppressing carcinogen activation, and trapping genotoxic agents. Yang et al. [180] demonstrated a high affinity to metals, alkaloids, and biological macromolecules, including lipids, carbohydrates, proteins, and nucleic acids. They capture and detoxify free radicals produced during various metabolic processes, including radiation and light exposure. Tea polyphenols conduct their inhibitory actions in different stages of mutagenesis, carcinogenesis, invasion, and tumor cell metastasis. They act as desmutagens and bioantimutagens intracellularly. Tea polyphenols also possess the ability to modulate, block, inhibit, or hinder DNA replication and repair.

\subsection{Green tea from a health perspective.}

Effects of green tea on humans, livestock, and laboratory experiments have been thoroughly studied, supporting the notion that green tea can support many health conditions. Green tea intake could be significantly correlated with a lower risk of stroke mortality and pneumonia. Moreover, the intake imparts a lower risk of cognitive impairment, depression, and psychological distress, which was further confirmed by other studies. Green tea consumption can also lower-down the risk of osteoporosis. Randomized placebo-controlled studies have shown that green tea decreases cardiovascular risk factors and disability prevention effectively [181-184].

\subsubsection{Anticancer Effects.}

Specialized studies have seen conflicting evidence between green tea and reducing the risk of cancer, while other studies did not find any sort of connection. Limited and heterogeneous clinical trials reported conflicting findings due to variations in diet, climate, and population [185]. Several population-based clinical trials have shown that green and black teas can have beneficial therapeutic effects against cancer. For example, Japanese people who frequently consume green tea are at lower risk of cancer incidence; however, the same test 
could not be used to determine whether green tea prevents cancer in people from other countries [186]. However, there exists a strong association between foods rich in phenolic compounds or flavonoids and their anticancer potential. Several clinical trials and published research suggest that polyphenols for tea or green tea may be responsible for cancer prevention [187]. Figure 3 elucidates the plausible anticancer mechanism of action of flavonoids, polyphenols, and terpenoids. These phytoconstituents are known to inhibit cell survival signaling pathways resulting in the downregulation of cyclin and CDK proteins. Major signaling cascades, such as mitogen-activated protein kinase (MAPK), mammalian target of rapamycin (mTOR), AKT serine/threonine-protein kinase B (AKT), matrix metalloproteinases and caspase-3/-8,-9 have been reported to be playing a significant role against metastasis [188].

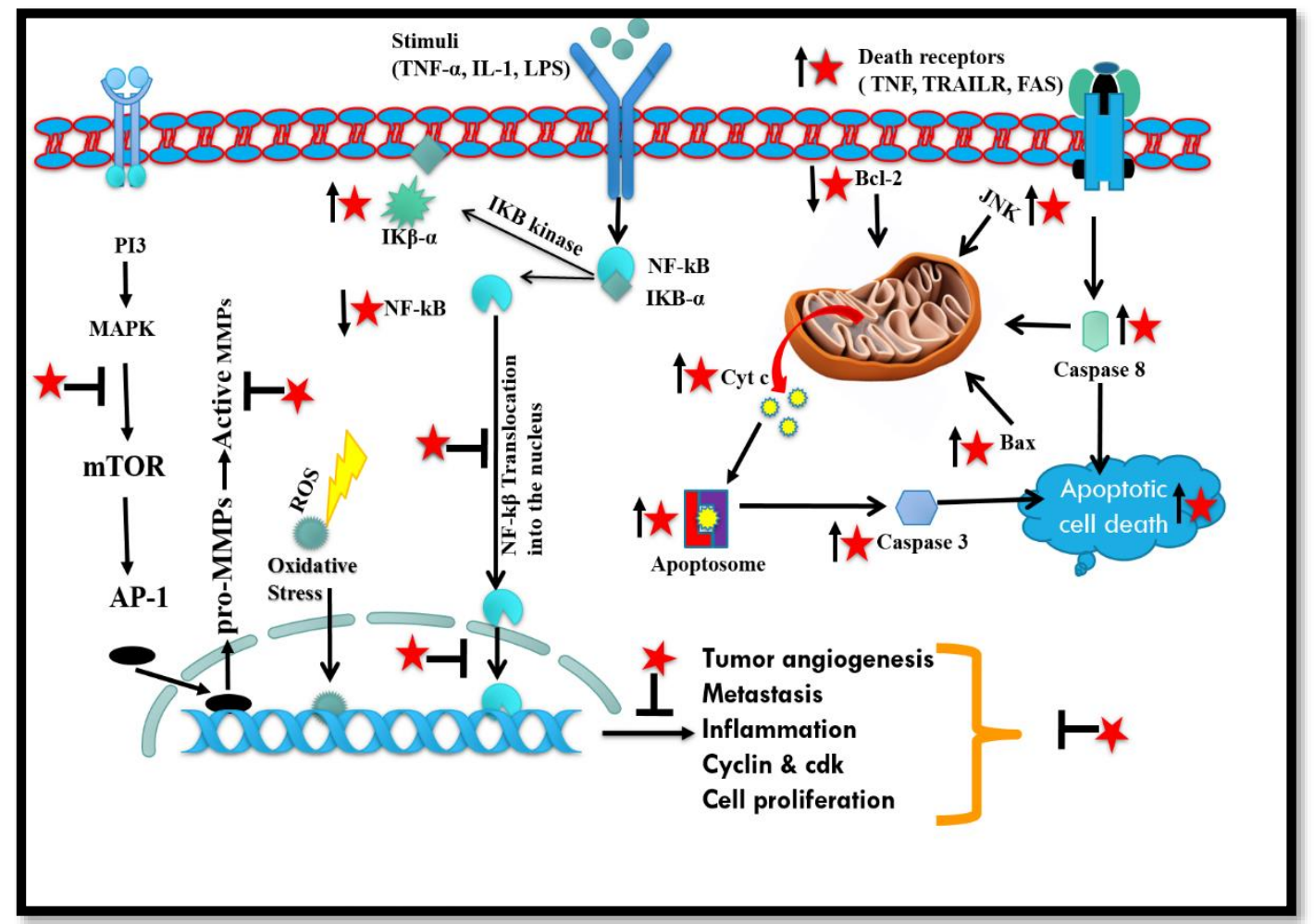

Figure 3. Schematic representation of the anticancer mechanism of action of flavonoids, polyphenols \& terpenoids. These phytoconstituents inhibit cellular survival pathways and downregulation of cyclin and CDK proteins. Major signaling cascades, such as mitogen-activated protein kinase (MAPK), mammalian target of rapamycin (mTOR), AKT serine/threonine-protein kinase B(AKT), matrix metalloproteinases and caspase-3/$8,-9$ have been reported as key players for their anti-malignancy potential.

\subsubsection{Bladder cancer.}

Some clinical trials explored the correlation between tea and bladder cancer. Women drinking black tea or powdered green tea were reported to be less likely to develop bladder cancer in one of the studies. Interestingly, the same group of researchers found patients with bladder cancer who had green tea or black tea, were having a higher survival rate than others [189].

\subsubsection{Esophageal cancer.}

One of the research groups from India showed that black tea consumption could lead to the development of oesophageal cancer, which can be well correlated with that of the 
Chinese cohort group who used to consume hot black tea. Throughout India, black tea is usually taken with milk that further neutralizes the beneficial effects of tea [190,191]. Furthermore, Catechin content in green tea is reported to be higher than black tea, which could further explain the contrary relationship between tea and esophageal cancer risk.

\subsubsection{Prostate cancer.}

Prostate cancer is a model candidate disease for chemoprevention as higher latency is diagnosed in men over 50 years of age [192]. Therefore, even a minor delay in cancer progression using chemopreventive therapy will improve the patient's quality of life [193]. Cultural, epidemiological, and migration studies further suggest that Asians are at a lower risk of cancer due to the regular consumption of green tea in comparison to Western societies [194]. Preclinical animal studies and lab reports also suggest the protective efficacy of green tea against prostate cancer $[142,195]$.

\subsubsection{Skin cancer.}

Naturally occurring plant products, i.e., polyphenols, were extensively used to prevent UV-induced skin photo-damage and skin cancer risk. Dietary polyphenols can be used as an ideal chemopreventive agent for various skin disorders because they have anti-inflammatory, immune-modulatory, and anti-oxidant properties. In addition, keeping in view of many carcinogenic environmental factors that are not so easy to regulate, people can change to a healthy lifestyle and good dietary behaviors along with the use of skin care products to avoid skin photo-damaging.

\subsubsection{Cervical cancer.}

It is the third most common malignancy in women worldwide, as this malignancy is considered to be the most common gynecological cancer in the developing world. By extensive and systematic use of cervical cytology screening, it was established that this malignancy affects women's lives during the time of their highest productivity in both developing and developed countries. It is recognized that regular fruits and vegetable intake can significantly reduce the epidemiological risk of cancer [196]. Further, the regular intake of green tea has also been reported to decrease the incidences of other types of cancer, including cervical cancer [197].

\subsubsection{Pancreatic cancer.}

Limited studies have suggested a link between green tea and pancreatic cancer. The hospital-based case-control analysis found no pancreatic cancer risk associated with the consumption of green tea in Japan [198]. A systematic study comprising of 100,000 Japanese adults up to 11 years and 233 incidences of cancer, found no association between green tea intake and pancreatic cancer risk [199]. Nonetheless, a higher percentage of mortality from pancreatic cancer was found in another retrospective study in Japan spanning up to 13 years with 292 incidences of pancreatic cancer (patients consuming < 1 cup/day of green tea) [200]. The epidemiological data available so far, are insufficient to conclude that green tea or black tea can protect against pancreatic cancer. 


\subsection{Antioxidative role of tea polyphenols.}

The antioxidant tea polyphenols and flavonoids were thought to be closely linked to their anti-carcinogenic activity. Reactive oxygen species (ROS), including superoxide and hydroxyl radicals, play key roles in carcinogenesis by muatgenizing DNA, altering gene expression, and affecting cell growth and distinction. Reports indicate that the green tea preparations inhibited the development of NNK-induced 12-o-tetradecanoylphorbol-1, 3acetate-induced hydrogen peroxide in mouse epidermis, and NNK-induced 8hydroxydeoxyguanosine in the mouse lung. In another study, tea preparations were shown to inhibit decarboxylase, protein kinase $\mathrm{C}$, lipoxygenase, and cyclo-oxygenase as well. The polyphenolic fractions present in tea and green tea were reported to inhibit the activation of carcinogens and growth-related signal transduction pathways, as demonstrated through in vitro and few in vivo studies [201,202]. Another study revealed the activities of glutathione peroxidase, catalase, glutathione S-transferase, NADPH-quinone oxidoreductase, uridine diphosphate-glucuronosyltransferase, and methoxyresorufin Odealkylase were increased in animals having oral tea intake. Tea preparation was reported to inhibit nitrosation in vitro studies as well as in humans [203], which could be a vital factor in combating other types of cancer, such as gastric cancer as well.

\subsection{Coffee polyphenols.}

Coffee polyphenols viz. Caffeic and chlorogenic acids were tested in vitro for their modulatory effects in two human breast cancer cell lines in order to check their effects on methylation of synthetic DNA substrates and the methylation status of the RAR $\beta$ promoter region [204]. DNA methylation was found to be inhibited by these coffee polyphenols in a concentration-dependent manner catalyzed by DNMT1, primarily by a non-competitive mechanism. Such polyphenolic compounds partly inhibit the methylation of RAR $\beta$ promoter region in MCF-7 and MAD-MB-231 human breast cancer cells. Caffeic acid phenethyl ester (CAPE), a catechol destroys different cancer cell types but is harmless to normal cells. Numerous studies have shown that CAPE's inhibitory effects occur both in vitro and in vivo in many cancer models such as colon cancer [205], lung cancer [206], melanoma [207], glioma [208], pancreatic cancer [209], gastric cancer [210], cholangiocarcinoma [211], and hepatocellular carcinoma [212].

\subsection{Sulforaphane.}

Broccoli is a good source of this phytochemical, which is having a dietary anticarcinogenic activity, including enhanced xenobiotic metabolism, cell cycle arrest, and apoptosis. Sulforaphane was also reported to control DNMT1 in colon cancer cells [213].

\subsection{Isothiocyanates.}

Isothiocyanates are also the dietary phytochemicals found in a wide variety of cruciferous vegetables having anti-cancer activity. Treatment with phenethylisothiocyanate, a gluconasturtiin metabolite derived from watercress, has been shown to lead to demethylation and GSTP1 re-expression [214], while treatment with various isothiocyanates has been shown to prevent oesophageal tumorigenesis [215]. 


\subsection{Curcumin.}

Curcumin is a polyphenolic compound with a variety of pharmacological effects, including antioxidant, anti-inflammatory, anti-proliferative, and anti-angiogenic activity. Curcumin was used in traditional remedies and Asian cooking for decades, giving the food the perfect yellow hue. It is well-established now that curcumin exhibits inhibitory effects on cyclo-oxygenases 1, 2 (COX-1, COX-2), lipoxygenase (LOX), TNF- $\alpha$, inducible nitric oxide synthase (iNOS) and NF- $\pi \mathrm{B}$ [216], suggestive of its potent anti-inflammatory role. Curcumin has also been shown to inhibit cancer growth, having a combination of anti-oxidant, antiproliferative, pro-apoptotic, and anti-angiogenic properties through the regulation of several pathway genes and molecules. Curcumin, however, displays limited bioavailability due to its poor absorption and rapid metabolism [217]. In order to improve the bioavailability and absorption, liposomal curcumin, curcumin nanoparticles, and other structural analogs of curcumin were synthesized and investigated to establish the absorption and anti-cancer activity of curcumin [218].

\subsection{Rosmarinic acid.}

Many Lamiaceae herbs commonly use it as culinary herbs. Oregano, basil, thyme, and peppermint contain a natural carboxylic acid antioxidant. Rosmarinic acid demonstrated a significant inhibitory effect on DNMT1 activity in MCF7 breast cancer cells in nuclear extracts. However, hypermethylated genes cannot be demethylated using this compound, such as RASSF1A, GSTP1, and HIN-1 [219].

\subsection{Resveratrol.}

It is a phytoalexin produced by many plants but can also be chemically synthesized due to its excellent medicinal properties, i.e., potential anti-cancer, anti-inflammatory, blood-sugarlowering, and other beneficial effects. Resveratrol is a poor DNMT activity inhibitor in MCF7 cell nuclear extracts as rosmarinic acid was unable to reverse methylation of multi-tumor suppressor genes [219]. Resveratrol increased the activity of adenosine analogs in MCF-7 cells to inhibit methylation and increase in RAR $\beta 2$ expression [220].

\section{Terpenoids}

Terpenoids are used in fragrance, flavor, pharmaceutical, and chemical industries and are the largest class of natural products with 25,000 chemical structures [221]. Terpenoids comprise of various subclasses based on their chemical properties, including monoterpenoids, sesquiterpenoids, diterpenoids, triterpenoids, and tetraterpenoids. Naturally, derived terpenoids have anti-cancer activities and used as a major bioactive component in conventional Chinese medicine, and the therapeutic efficacy of such compounds has been confirmed by centuries of clinical use.

\subsection{Monoterpenoids.}

\subsubsection{Limonene.}

It can be extracted mainly from essential citrus fruit oils and plant organisms. It is used as cleaning agents and fragrance additives in industries. Limonene occurs in two active forms, 
L-limonene and D-limonene, which are mirror images of each other. D-limonene is mainly used in cancer research as it contains various citrus oils (e.g., lemon, peach, mandarin, lime, grapefruit). Moreover, it is known to prevent liver cancer by increasing liver enzyme levels that can detoxify carcinogens [222].

The therapeutic effects of D-limonene have been well documented for the last two decades. It was previously shown to significantly inhibit a variety of malignancies, including pancreatic, stomach, colon, skin, and liver cancer. D-limonene was reported to prevent tumor growth and metastasis in an orthotopic mouse model for human gastric cancer, probably through its anti-angiogenic, pro-apoptotic, and antioxidant activities. The combination of Dlimonene and cytotoxic agents such as fluorouracil (5-FU) and docetaxel, seemed more successful than any single treatment against cancer [223]. D-limonene has been shown to inhibit 3-hydroxy-3-methylglutanyl coenzyme A (HMGCo-A) reductase [224], which inhibits the isoprenylation of small G-proteins such as p21 [225]. This influence is thought to contribute to the effectiveness of D-limonene in chemoprevention and cancer care. However, this hypothesis does not seem relevant to all types of cancers [226]. Other apoptotic studies stated that D-limonene up-regulates Bax protein expression, cytochrome c release from mitochondria, and caspase- 3 and 9 cleavages. Such evidence indicates that mitochondrial mortality is mainly linked with D-limonene-induced apoptosis [227].

\subsubsection{Cantharidin.}

One of the few non-plant-derived terpenoids that have been reported as an anti-cancer agent [228]. This is a natural defensive toxin produced by as many as 1,500 species of blister beetle with perhaps the best-known example being the Spanish fly, Cantharis vesicatoria [229]. This bears intrinsic similarities with extremely toxic synthetic herbicides such as endothelial, endothelial anhydride, and endothelial thioanhydride. Indeed, all these herbicides are considered respiratory carcinogens, and thus a structural similarity exists that involves cantharidin's carcinogenic action. Anti-cancer cantharidine properties have been associated with strong in vitro anti-cancer activity against a wide variety of cancer cells, including leukemia, colorectal carcinoma, hepatoma, bladder carcinoma, and breast cancer [230]. Despite its well-known anti-cancer properties, cantharidine's therapeutic use is limited due to its serious side effects and extreme toxicity. The chemical modifications of cantharidin have been recommended for therapeutic use in order to produce analogs with similar anti-cancer properties while having a less detrimental effect on non-cancer or normal cells. Serine/threonine-protein phosphatase 1 (PP1) and 2A (PP2A) have been the best-known cantharidin targets so far. Potent and selective inhibitors of these two phosphatases have long been recognized, which play an important role in cell cycle regulation, apoptosis, and celllipids determination. Cantharidin has been reported to inhibit the function of PP1 and PP2A distilled catalytic subunits at submicromolar levels [231].

\subsection{Sesquiterpenoids.}

\subsubsection{Artemisinin and its derivatives.}

This is an active terpenoid derived from Chinese herb Artemisia annua L., commonly used in East Asia and Africa for malaria treatment. This drug, along with its variants (artesunate, artemether, and arteether), has been seen to have higher intrinsic antimalarial activity and have substituted quinine in many nations as a therapy for falciparum malaria, 
typically paired with other antimalarial medicines. Moreover, Artemisinin and its derivatives (ARTs) were used to regulate schistosomiasis, immunosuppression, and cancer treatment, as well [232,233]. Chemically, artemisinin is a trioxane lactone sesquiterpene forming a peroxide bridge for its function. The anti-cancer properties of Dihydroartemisinin (DHA) and artesunate have also been documented previously. ARTs are known to prevent the spread of cancer in a variety of malignancies, including leukemia, breast cancer, cervical cancer, prostate cancer, colon cancer, hepatoma, gastric, melanoma, and lung cancer [234,235]. These appear to bypass multidrug-resistant (MDR) cancer cells displaying significant anti-cancer potential [236,237]. Many xenograft animal models have demonstrated the anti-cancer potential of ART's in vivo as well [238]. ARTs have been successfully used in carboplatin or gemcitabine-sensitized combinatorial chemotherapy in xenograft tumor models [239,240]. In another study, deferoxaminemesilate powder, which is an iron chelator, was shown to retain DHA-induced apoptosis or proliferative inhibition [241]. Tumor suppressor p16 and the antioxidant protein catalase were found to make ART cells immune, while the oncoprotein c-MYC was reported to sensitize ART cells [33]. Nonetheless, the evidence clearly supports the anticancer properties exhibited by ARTs. ARTs mediate G1 cell cycle inhibition by affecting cyclin D, cyclin E, CDK2, CDK4, p21, p27, NF-kB, etc. [242,243] and by stimulating p38 MAPK enhancing Fas expression and caspase stimulation [244]. ARTs also regulate urokinase plasminogen activator (u-PA), MMP2, MMP7, and MMP9, avb3 integrins, and vascular endothelial growth factor (VEGF), thus inhibiting angiogenesis, metastasis, and invasion [245].

\subsection{Diterpenoids.}

\subsubsection{Tanshinone IIA.}

These are key diterpenoid agents commonly used in cardiovascular disease control [246]. Salvia miltiorrhiza Bunge derived diterpenoid analog, tanshinone IIA is the most common and well studied for its in vitro and in vivo anti-cancer activities as seen in most human carcinomas including leukemia, breast cancer, colon cancer, and hepatocellular carcinoma [247]. Tanshinone also demonstrated synergistic effects when paired with other anti-cancer medicines, including doxorubicin and cisplatin [248]. Tanshinone IIA is a minor DNA groove binder that damages the DNA structure and effectively prevents RNAPII attachment to DNA and initiates RNAPII phosphorylation. Such a process is the molecular basis of tanshinone IIA's anti-cancer property. Tanshinone IIA also induces differentiation of several types of cancer cells $[249,250]$ and prevents cancer cell invasion and metastasis by reducing levels of $\mathrm{u}-\mathrm{PA}, \mathrm{MMP}$, MMP9 and NF-kB and increasing concentrations of TIMP1 and TIMP2 metalloproteinase inhibitors [251].

\subsubsection{Triptolide.}

Tripterygium wilfordii Hook F. derived ripoxidetriptolide or 'thunder god vine' was explored for analyzing its potential as an anti-cancer drug. This medicinal plant's derivatives have been used in traditional Chinese medicine for a wide range of diseases, from asthma to inflammatory disorders. Besides its well-known immune-suppressive and anti-inflammatory functions, triptolide also has significant anti-proliferative effects [252]. In vivo anti-cancer efficacy of triptolide has been verified in several pre-clinical trials in xenograft animal models. Triptolide and its derivatives were also used in clinical cancer therapy trials. Evidence suggests that triptolide has a major effect on cancer cell transcriptional machinery, which may be 
partially responsible for anticancer activities of triptolide. This influences a variety of factors in transcription, including NF-kB, p53, NF-AT and HSF-1 [253,254]. More recent research by Wang et al. [255] found that by inducing proteasome-dependent degradation of the largest RNA polymerase II (Rpbl) subunit in cancer cells, triptolide inhibits global gene transcription. Despite all these advances, the exact triptolide targets in cancer cells remain elusive.

Different attempts have been made to classify the molecular targets of triptolide that have contributed to the discovery of a variety of possible molecular targets, including polycystin-2 calcium channel [256] comprising of a 90-kDa nuclear protein [257] and a newly identified human XPB, a TFIIH transcription factor subunit [258]. Triptolide's covalent binding to XPB and the consequent inhibition of ATPase activity of XPB is evident in triptolide's known cellular and physiological behaviors. Furthermore, triptolide has been shown to cause DNA damage in cancer cells, possibly due to faulty excision nucleotide repair because of XPB inhibition.

\subsubsection{Andrographolide.}

Andrographolide is the primary bioactive ingredient of Andrographis paniculata, a common Chinese plant used in many Asian countries to treat colds, cough, laryngitis, and diarrhea. Bioactive Andrographis paniculata molecules, including andrographolide, displayed varying degrees of anti-inflammatory and anti-cancer efficacies both in vitro and in vivo models $[259,260]$. Andrographolide was reported to have beneficial effects on diabetes as it can minimize blood glucose levels by increasing glucose usage [261]. To date, NF-kB transmission blockage has been suggested to counteract many of andrographolide's beneficial effects. NF$\mathrm{kB}$ inhibitory activity is partly due to its covalent regulation of reduced cysteine in the p50 oligonucleotide-binding pocket, the NF-kB transcription factor [262]. Cytokine, chemokine, adhesion molecules, nitric oxide, and lipid mediators have been shown to decrease andrographolide levels by inhibiting the NF-kB signaling pathway [259]. NF-kB inhibition induces attenuated neointimal hyperplasia in arterial restenosis by controlling NF-kB targets gene expressions, such as E-selectin and vascular adhesion molecule-1 [249]. Andrographolide also exhibits protective effects on beta cells through its NF-kB inhibitory and antioxidant activity. Andrographolide was also found to decrease p65 phosphorylation in Ser536 and IkBa in Ser32/36, resulting in inhibition of aberrant NF-kB activation, attenuation of neoplastic cell proliferation, and promotion of human-language squamous cell carcinoma apoptosis, with concomitant reduction of NF-kB targeting in vitro [263]. In addition to interference in NF-kB signaling, andrographolide therapy was also found to affect a wide variety of signaling pathways and factors, including JAK-STAT and PI3 K inhibition, suppression of HSP90, cyclines and cycline-dependent kinases, metalloproteinases, growth factors, and activation of tumor suppressor proteins $\mathrm{p} 53$ and $\mathrm{p} 21$.

\subsubsection{Oridonin.}

Oridonin is a biologically active ingredient isolated from Rabdosiarubescens, a Chinese herb for mouth and throat washing. Recently, many solid tumors, including hepatic cancer, skin carcinoma, osteoma, and colorectal cancer, have beneficial effects on oridonin. Oridonin prevents T-cell leukemia in adolescents, acute lymphoblastic leukemia, chronic lymphocytic leukemia, non-Hodgkin lymphoma, and multiple myeloma cells [264]. Anti-cancer activity in vivo was shown in a colorectal colostomy model [265]. Inhibiting binding NF-kB DNA 
activity, apoptosis is considered primarily responsible for oridonin-mediated cancer cell death associated with blocking of NF-kB signaling pathway [264]. More experiments in a colorectal tumor model showed that after oridonin therapy, the levels of the activator protein-1 (AP-1) decreases, followed by NF-kB and p38 down-regulation. These results indicate that AP-1 downregulation is the initial response to oridonin therapy. NF-kB expression and mitogenic protein kinase pathways impede tumor development [265]. These effects also lead to oridonininduced cancer cell apoptosis [266]. Studies have shown that, besides apoptosis, oridonintreated cancer cells also undergo autophagy. However, the associations of these events with oridonin therapy are still unclear. Autophagy inhibition was shown to reduce oridonin-induced apoptosis in p53-dependent human sarcoma cells HT1080, suggesting a combination of oridonin-induced apoptosis and autophagy to mediate cell death [267]. Nonetheless, 3-MA autophagy or siRNA inhibition against LC3 and becline 1 in murine fibrosarcoma L929 cells facilitated oridonin-induced apoptosis [268], consistent with another finding that autophagy increases p38 MAPK-NF-kB signaling cell survival and prevents ROS-mediated oridonininduced apoptosis [269]. A more recent study showed that N-acetylcysteine, a ROS scavenger, significantly decreases apoptosis and autophagia in human cervical carcinoma cells [270]. The reasons for these variations remain uncertain and may be due to cancer cell existence or heterogeneity differences.

\subsection{Triterpenoids.}

\subsubsection{Celastrol.}

The bioactive terpenoid from Tripterygium wilfordii Hook, also known as tripterine. Has been known to possess a variety of biological activities viz. anti-oxidant, anti-cancer, and anti-inflammatory [271]. Celastrol is the one that has attracted much interest, particularly against inflammation. Estostrol has been used in animal models of collagen-induced arthritis, Alzheimer's disease, asthma, and lupus [272]. Several studies have successfully shown the celastrol inhibition of the synthesis and secretion of pro-inflammatory cytokines and adhesion molecules [273]. Celastrol also decreases inflammation and oxidative stress in vascular smooth muscle cells that are caused by hypertension. Heme oxygenase-1 has increasingly been recognized as a crucial factor for mediating estostrol's anti-inflammatory effects [274]. Estostrol therapy may inhibit different signaling pathways and can contribute to their anticancer effects as well.

\subsubsection{Cucurbitacins.}

Cucurbitacin and its derivatives form a class of cucurbitane, which are effective insect attractants that are commonly used as bait in insecticides [275]. Studies show that cucurbitacins have important human pharmacological activities, including anti-cancer, anti-inflammatory, and hepatoprotective effects [248]. Accumulated studies have shown that most cucurbitacins prevent the spread of multiple tumor cells at nanomolar levels in vitro. Cucurbitacins cause cell cycle arrest, mainly G2/M [248] and S phase arrest [276]. Additionally, some studies show that cucurbitacins induce differentiation in multiple tumor cell lines [277]. More recent research indicated that cucurbitacin B causes autophagy but has been viewed as a survival aid [278]. While several pieces of evidence suggested their widespread role, the effects of cucurbitacins on anti-angiogenesis were not well known. Cucurbitacins actively affect tumor cell invasion and in vitro migration, further inhibiting metastasis in vivo $[279,280]$. Future research must 
emphasize on combining cucurbitacin therapy with another widely prescribed chemotherapeutic agent. Once paired with gemcitabine [281], cisplatin, doxorubicin, 5fluorouracil, paclitaxel [277], and docetaxel [282] Cucurbitacins showed synergistic effects both in vitro and in vivo models. The mechanisms behind cucurbitacin's anti-tumor activity need to be further researched.

\subsubsection{Alisol.}

Alisol derivatives are special triterpenoid-type protostane compounds isolated from Alismaorientalis (Sam.) Juzep rhizome, a well-known herbal medication for the treatment of hypertension, hyperlipidemia, and urological diseases in East Asia [283-285]. Such compounds have now gained growing attention because of their possible activities against cancer [286]. Alisol B induces endoplasmic reticulum stress, autophagy, and apoptosis in many cancer cell lines, with $\mathrm{Ca}^{2+}$ ATPase as its key molecular target [287]. Alisol B 23-acetate mediates G2/M cell cycle arrest and induces apoptosis in cancer cells and inhibits the PI3K/Akt signaling pathway, Bax/Bcl-2 ratio up-regulation and caspase activation that contributes to its anti-cancer effects [288]. Furthermore, alisol B 23-acetate is suggested as a potential MDR-reversing agent that restores the sensitivity of MDR cells [289].

\subsubsection{Pachymic acid.}

This is a lanostane-type triterpenoid derived from Poria cocos and is known to have anti-inflammatory [290] and anticancer activities [291,292]. Data on anti-cancer activities and the pachymic acid action mechanism are minimal. It shows cytotoxicity and induces apoptosis in A549, DU145, and HT29 cells (human lung cancer cells, human prostate cancer cells, colon cancer cells, respectively [291,293]. Pachymic acid treatment also activates PARP, caspases9, and caspases-3 [294]. Inhibitory effects on both DNA topoisomerase I and II have also seen [295]. Pachymic acid suppresses invasion of non-lethal MDA-MB-231 and MCF-7 breast carcinoma cells, associated with decreased MMP9 secretion [296]. Pachymic acid was also found to decrease PMA-caused NF-kB transcriptional activity [291,297].

\subsection{Tetraterpenoids.}

Carotenoids are the most common tetraterpenoids, with over 600 recognized natural structural variants. They are natural fat-soluble pigments that vividly paint plants and animals [298]. Carotenoids are structurally differentiated by three aspects such as (i) either being simple unsaturated hydrocarbons with a particular lycopene structure or their corresponding oxygenated analogs, typically referred to as xanthophylls; (ii) eight isoprene units are found to be linked head-to-tail in lycopene to give it a conjugated network that is basically responsible for the chromophoric character (iii) at both the molecule terminals, lycopene cyclisation results in a bicyclic hydrocarbon commonly known as $\beta$-carotene that occurs most abundantly in higher plants [299,300]. The dietary intake of carotenoids was reported to decrease the risk of several cancers, suggesting preventive carotenoid functions in cancer. Pre-clinical research has found that carotenoid therapeutic functions such as $\beta$-carotene, $\alpha$-carotene, lycopene, lutein, zeaxanthin, $\beta$-cryptoxanthin, fucoxanthin, canthaxanthin, and astaxanthin were all anticarcinogenic [300,301]. 


\subsubsection{Lycopene.}

Lycopene is an open-chain hydrocarbon containing 11 conjugated and 2 nonconjugated double bonds arranged in a linear series, primarily from tomatoes [302]. Clinical studies have examined the ability of tomato-derived carotenoid lycopene for the anti-cancer function of natural compounds extracted from the human diet [302,303]. A Phase II clinical trial investigated the effectiveness of lycopene alone or with soy isoflavones on serum prostatespecific antigen (PSA) levels in men with prostate cancer. Lycopene and soy isoflavones delayed the growth of hormone-refractory and hormone-sensitive prostate cancer [304]. In addition, a small, randomized clinical trial found that lycopene supplementation can increase lycopene levels in prostate tissue, modulate biomarkers of growth and differentiation, and decrease aggressive clinical parameters of clinically located prostate cancer [304]. ROS scavenging has shown that lycopene exhibits antioxidant effects, which helps lycopene to prevent lipid peroxidation and DNA damage. At the same time, lycopene induces enzymes from the cellular antioxidant protection systems by activating the transcription mechanism for the anti-oxidant response factor [305]. The molecular mechanism which accounts for lycopene's anti-cancer activity remains unclear despite the increasingly accumulating data. Recent work using proteomic analysis found that lycopene modulates the expression of a wide variety of proteins, including proteins from the cell cycle and heat shock proteins [306]. This strategy can represent a powerful approach for gaining mechanistic insights into lycopene's mode of action.

\section{Conclusions}

Natural dietary phytochemicals were commonly used in in-vitro, in-vivo, and preclinical cancer research, which has shown varying efficacy in the trials. However, a wide range of mechanistic experiments has shown significant chemopreventive effects of phytochemicals. Cancer chemoprevention has remained an appealing approach as far as the treatment with natural phytochemicals is concerned. More attempts are urgently needed in order to better understand their potencies, pharmacokinetic effectiveness, pharmacodynamic responses, metabolism, toxicity, drug-drug interactions, polymorphism, and formulations. Natural dietary phytochemicals remained a promising, active area of potential research. Nevertheless, more research is required in this field to determine the most suitable targets for these phytochemicals to carry out tailor-made clinical studies that produce reliable results. Therefore, using phytochemical supplements in focus groups and patients is a very effective tool for cancer prevention and care. Bioavailability of polyphenols in the human intestine is the main concern mainly influenced by their degree of polymerization. The growth, bioavailability and biological activity of phenolic metabolites depend primarily on gut microbiota, particularly after ingestion of high-molecular-weight polyphenols in food. While extensive research has been conducted on the broad range of health-promoting properties of dietary polyphenols, their impact on intestinal ecology control and the two-way relationship "polyphenols $\leftrightarrow$ microbiota" is still poorly understood. Some studies have documented the impact of dietary polyphenols on human gut microbiota, mostly focusing on single polyphenol molecules and selected populations of bacteria. Further research is required in this field, focusing on reciprocal interactions between gut microbiota and polyphenols with mechanisms of action and the effects of these interactions on human health. 


\section{Funding}

This research received no external funding.

\section{Acknowledgments}

We sincerely apologize to those whose work could not be cited owing to space limitations. The authors are grateful to the M.M. (Deemed to be University) for providing the requisite platform to write this article.

\section{Conflicts of Interest}

The authors declare no conflict of interest.

\section{References}

1. Sporn, M.B.; Dunlop, N.; Newton, D.; Smith, J. Prevention of chemical carcinogenesis by vitamin A and its synthetic analogs (retinoids). In: Proceedings of Federation proceedings. 1976; pp. 1332-1338.

2. Rodríguez-García, C.; Sánchez-Quesada, C.; Gaforio, J.J. Dietary flavonoids as cancer chemopreventive agents: An updated review of human studies. Antioxidants 2019, 8, https://doi.org/10.3390/antiox8050137.

3. Caban, M.; Owczarek, K.; Chojnacka, K.; Lewandowska, U. Overview of polyphenols and polyphenol-rich extracts as modulators of IGF-1, IGF-1R, and IGFBP expression in cancer diseases. Journal of Functional Foods 2019, 52, 389-407, https://doi.org/10.1016/j.jff.2018.11.003.

4. Ginwala, R.; Bhavsar, R.; Chigbu, D.G.I.; Jain, P.; Khan, Z.K. Potential role of flavonoids in treating chronic inflammatory diseases with a special focus on the anti-inflammatory activity of apigenin. Antioxidants 2019, 8, https://doi.org/10.3390/antiox8020035.

5. Kolodziejczyk, A.A.; Zheng, D.; Elinav, E. Diet-microbiota interactions and personalized nutrition. Nature Reviews Microbiology 2019, 17, 1-12, https://doi.org/10.1038/s41579-019-0256-8.

6. Bulut, O.; Akın, D.; Sönmez, Ç.; Öktem, A.; Yücel, M.; Öktem, H.A. Phenolic compounds, carotenoids, and antioxidant capacities of a thermo-tolerant Scenedesmus sp.(Chlorophyta) extracted with different solvents. Journal of Applied Phycology 2019, 31, 1675-1683, https://doi.org/10.1007/s10811-018-1726-5.

7. Górniak, I.; Bartoszewski, R.; Króliczewski, J. Comprehensive review of antimicrobial activities of plant flavonoids. Phytochemistry Reviews 2019, 18, 241-272, https://doi.org/10.1007/s11101-018-9591-z.

8. Khalilpourfarshbafi, M.; Gholami, K.; Murugan, D.D.; Sattar, M.Z.A.; Abdullah, N.A. Differential effects of dietary flavonoids on adipogenesis. European journal of nutrition 2019, 58, 5-25, https://doi.org/10.1007/s00394-018-1663-8.

9. Harris, Z.; Donovan, M.G.; Branco, G.M.; Limesand, K.H.; Burd, R. Quercetin as an emerging antimelanoma agent: a four-focus area therapeutic development strategy. Frontiers in nutrition 2016, 3, https://doi.org/10.3389/fnut.2016.00048.

10. Chahar, M.K.; Sharma, N.; Dobhal, M.P.; Joshi, Y.C. Flavonoids: A versatile source of anticancer drugs. Pharmacognosy reviews 2011, 5, https://doi.org/10.4103/0973-7847.79093.

11. Amawi, H.; Ashby, C.R.; Tiwari, A.K. Cancer chemoprevention through dietary flavonoids: what's limiting? Chinese journal of cancer 2017, 36, https://doi.org/10.1186/s40880-017-0217-4.

12. Wang, Y.; Xu, Z.; Wu, Y.; Li, M.; Pang, S.; Liang, Z.; Ni, Y. Effect of Weakly Basic Conditions on the Separation and Purification of Flavonoids and Glycosides from Chrysanthemum morifolium Tea. Molecules 2019, 24, https://doi.org/10.3390/molecules24020297.

13. Hodek, P.; Trefil, P.; Stiborová, M. Flavonoids-potent and versatile biologically active compounds interacting with cytochromes P450. Chemico-biological interactions 2002, 139, 1-21, https://doi.org/10.1016/s0009-2797(01)00285-x.

14. Hertog, M.G.; Hollman, P.C.; Van de Putte, B. Content of potentially anticarcinogenic flavonoids of tea infusions, wines, and fruit juices. Journal of agricultural and food chemistry 1993, 41, 1242-1246, https://doi.org/10.1021/jf00032a015.

15. Gontijo, V.S.; dos Santos, M.H.; Viegas, J. Biological and chemical aspects of natural biflavonoids from plants: a brief review. Mini reviews in medicinal chemistry 2017, 17, 834-862, https://doi.org/10.2174/1389557517666161104130026.

16. Kumar, S.; Pandey, A.K. Chemistry and biological activities of flavonoids: an overview. The Scientific World Journal 2013, 2013, https://doi.org/10.1155/2013/162750.

17. Neuhouser, M.L. Dietary flavonoids and cancer risk: evidence from human population studies. Nutrition and cancer 2004, 50, 1-7, https://doi.org/10.1207/s15327914nc5001_1.

18. Ohga, N.; Hida, K.; Hida, Y.; Muraki, C.; Tsuchiya, K.; Matsuda, K.; Ohiro, Y.; Totsuka, Y.; Shindoh, M. Inhibitory effects of epigallocatechin-3 gallate, a polyphenol in green tea, on tumor-associated endothelial 
cells and endothelial progenitor cells. Cancer science 2009, 100, 1963-1970, https://doi.org/10.1111/j.13497006.2009.01255.x.

19. Manthey, J.A.; Guthrie, N.; Grohmann, K. Biological properties of citrus flavonoids pertaining to cancer and inflammation. Current medicinal chemistry 2001, 8, 135-153, https://doi.org/10.2174/0929867013373723.

20. Lee, W.R.; Shen, S.C.; Lin, H.Y.; Hou, W.C.; Yang, L.L.; Chen, Y.C. Wogonin and fisetin induce apoptosis in human promyeloleukemic cells, accompanied by a decrease of reactive oxygen species, and activation of caspase 3 and Ca2+-dependent endonuclease. Biochemical pharmacology 2002, 63, 225-236, https://doi.org/10.1016/s0006-2952(01)00876-0.

21. Schindler, R.; Mentlein, R. Flavonoids and vitamin E reduce the release of the angiogenic peptide vascular endothelial growth factor from human tumor cells. The Journal of nutrition 2006, 136, 1477-1482, https://doi.org/10.1093/jn/136.6.1477.

22. Shapiro, A.B.; Ling, V. Effect of quercetin on Hoechst 33342 transport by purified and reconstituted Pglycoprotein. Biochemical pharmacology 1997, 53, 587-596, https://doi.org/10.1016/s0006-2952(96)00826$\mathrm{x}$.

23. Hwang, K.A.; Choi, K.C. Anticarcinogenic effects of dietary phytoestrogens and their chemopreventive mechanisms. Nutrition and cancer 2015, 67, 796-803, https://doi.org/10.1080/01635581.2015.1040516.

24. Miltyk, W.; Craciunescu, C.N.; Fischer, L.; Jeffcoat, R.A.; Koch, M.A.; Lopaczynski, W.; Mahoney, C.; Crowell, J.; Paglieri, J.; Zeisel, S.H. Lack of significant genotoxicity of purified soy isoflavones (genistein, daidzein, and glycitein) in 20 patients with prostate cancer. The American Journal of Clinical Nutrition 2003, 77, 875-882, https://doi.org/10.1093/ajcn/77.4.875.

25. Kim, G.Y.; Suh, J.; Jang, J.H.; Kim, D.H.; Park, O.J.; Park, S.K.; Surh, Y.J. Genistein Inhibits Proliferation of BRCA1 Mutated Breast Cancer Cells: The GPR30-Akt Axis as a Potential Target. Journal of cancer prevention 2019, 24, 197-207, https://doi.org/10.15430/jcp.2019.24.4.197.

26. Sharma, V.; Sharma, A.K.; Punj, V.; Priya, P. Recent nanotechnological interventions targeting PI3K/Akt/mTOR pathway: A focus on breast cancer. In: Proceedings of Semin Cancer Biol. 2019; pp. 133146, https://doi.org/10.1016/j.semcancer.2019.08.005.

27. Lozada-García, M.C.; Enríquez, R.G.; Ramírez-Apán, T.O.; Nieto-Camacho, A.; Palacios-Espinosa, J.F.; Custodio-Galván, Z.; Soria-Arteche, O.; Pérez-Villanueva, J. Synthesis of Curcuminoids and Evaluation of Their Cytotoxic and Antioxidant Properties. Molecules 2017, https://doi.org/10.3390/molecules22040633.

28. Ahmad, N.; Gali, H.; Javed, S.; Agarwal, R. Skin cancer chemopreventive effects of a flavonoid antioxidant silymarin are mediated via impairment of receptor tyrosine kinase signaling and perturbation in cell cycle progression. Biochemical and biophysical research communications 1998, 247, 294-301, https://doi.org/10.1006/bbrc.1998.8748.

29. Zhu, W.; Zhang, J.-S.; Young, C.Y. Silymarin inhibits function of the androgen receptor by reducing nuclear localization of the receptor in the human prostate cancer cell line LNCaP. Carcinogenesis 2001, 22, 13991403, https://doi.org/10.1093/carcin/22.9.1399.

30. Li, L.; Zeng, J.; Gao, Y.; He, D. Targeting silibinin in the antiproliferative pathway. Expert opinion on investigational drugs 2010, 19, 243-255, https://doi.org/10.1517/13543780903533631.

31. Surai, P. Silymarin as a natural antioxidant: an overview of the current evidence and perspectives. Antioxidants 2015, 4, 204-247, https://doi.org/10.3390/antiox4010204.

32. Harwood, M.; Danielewska-Nikiel, B.; Borzelleca, J.; Flamm, G.; Williams, G.; Lines, T. A critical review of the data related to the safety of quercetin and lack of evidence of in vivo toxicity, including lack of genotoxic/carcinogenic properties. Food and chemical toxicology 2007, 45, 2179-2205, https://doi.org/10.1016/j.fct.2007.05.015.

33. Sertel, S.; Eichhorn, T.; Sieber, S.; Sauer, A.; Weiss, J.; Plinkert, P.K.; Efferth, T. Factors determining sensitivity or resistance of tumor cell lines towards artesunate. Chemico-biological interactions 2010, 185, 42-52, https://doi.org/10.1016/j.cbi.2010.02.002.

34. Wang, S.F.; Wu, M.Y.; Cai, C.Z.; Li, M.; Lu, J.H. Autophagy modulators from traditional Chinese medicine: mechanisms and therapeutic potentials for cancer and neurodegenerative diseases. Journal of ethnopharmacology 2016, 194, 861-876, https://doi.org/10.1016/j.jep.2016.10.069.

35. Zhao, Y.; Fan, D.; Zheng, Z.P.; Li, E.T.; Chen, F.; Cheng, K.W.; Wang, M. 8-C-(E-phenylethenyl) quercetin from onion/beef soup induces autophagic cell death in colon cancer cells through ERK activation. Molecular nutrition \& food research 2017, 61, https://doi.org/10.1002/mnfr.201600437.

36. Egert, S.; Rimbach, G. Which sources of flavonoids: complex diets or dietary supplements? Advances in Nutrition 2011, 2, 8-14, https://doi.org/10.3945/an.110.000026.

37. Shukla, S.; Gupta, S. Apigenin: a promising molecule for cancer prevention. Pharmaceutical research 2010 , 27, 962-978, https://doi.org/10.1007/s11095-010-0089-7.

38. Swathi, P.; Nagendra Sastry, Y.; Eswar Kumar, K.; Dhananjaya Bhadrapura, L.; Mohammad, A.K.; Luciana, S.; Marcus, T.S.; Ghulam Md, A.; Rao, B.S.B.; Sarala Kumari, D.; Gorla, V.R.; Vadim, V.T.; Sarat Babu, I.; Gjumrakch, A. Preventive and Therapeutic Potentials of Anthocyanins in Diabetes and Associated Complications. Current Medicinal Chemistry 2018, 25, 5347-5371, https://doi.org/10.2174/0929867325666171206101945. 
39. Bordoloi, D.; Monisha, J.; Roy, M.; Padmavathi, G.; Banik, K.; Harsha, C.; Wang, H.; Kumar, A.P.; Arfuso, F.; Kunnumakkara, A.B. An Investigation on the Therapeutic Potential of Butein, A Tretrahydroxychalcone Against Human Oral Squamous Cell Carcinoma. Asian Pacific journal of cancer prevention: APJCP 2019, 20, https://doi.org/10.31557/APJCP.2019.20.11.3437.

40. Sharma, A.K.; Sharma, V.R.; Gupta, G.K.; Ashraf, G.M.; Kamal, M.A. Advanced glycation end products (AGEs), glutathione and breast cancer: Factors, mechanism and therapeutic interventions. Current drug metabolism 2019, 20, 65-71, https://doi.org/10.2174/1389200219666180912104342.

41. Kürbitz, C.; Heise, D.; Redmer, T.; Goumas, F.; Arlt, A.; Lemke, J.; Rimbach, G.; Kalthoff, H.; Trauzold, A. Epicatechin gallate and catechin gallate are superior to epigallocatechin gallate in growth suppression and anti-inflammatory activities in pancreatic tumor cells. Cancer science 2011, 102, 728-734, https://doi.org/10.1111/j.1349-7006.2011.01870.x.

42. Thilavech, T.; Adisakwattana, S. Cyanidin-3-rutinoside acts as a natural inhibitor of intestinal lipid digestion and absorption. BMC complementary and alternative medicine 2019, 19, 1-10, https://doi.org/10.1186/s12906-019-2664-8.

43. Das, D.; Sarkar, S.; Bordoloi, J.; Wann, S.B.; Kalita, J.; Manna, P. Daidzein, its effects on impaired glucose and lipid metabolism and vascular inflammation associated with type 2 diabetes. Biofactors 2018, 44, 407417, https://doi.org/10.1002/biof.1439.

44. Lamartiniere, C.A.; Wang, J.; Smith-Johnson, M.; Eltoum, I.E. Daidzein: bioavailability, potential for reproductive toxicity, and breast cancer chemoprevention in female rats. Toxicological Sciences 2002, 65, 228-238, https://doi.org/10.1093/toxsci/65.2.228.

45. Estévez, L.; Mosquera, R.A. Molecular structure and antioxidant properties of delphinidin. The Journal of Physical Chemistry A 2008, 112, 10614-10623, https://doi.org/10.1021/jp8043237.

46. Kim, J.; Nguyen, T.T.H.; Kim, N.M.; Moon, Y.H.; Ha, J.M.; Park, N.; Lee, D.G.; Hwang, K.H.; Park, J.S.; Kim, D. Functional properties of novel epigallocatechin gallate glucosides synthesized by using dextransucrase from Leuconostoc mesenteroides B-1299CB4. Journal of agricultural and food chemistry 2016, 64, 9203-9213, https://doi.org/10.1021/acs.jafc.6b04236.

47. Legeay, S.; Rodier, M.; Fillon, L.; Faure, S.; Clere, N. Epigallocatechin gallate: a review of its beneficial properties to prevent metabolic syndrome. Nutrients 2015, 7, 5443-5468, https://doi.org/10.3390/nu7075230.

48. Youns, M.; Hegazy, W.A.H. The natural flavonoid fisetin inhibits cellular proliferation of hepatic, colorectal, and pancreatic cancer cells through modulation of multiple signaling pathways. PLoS One 2017, 12, https://doi.org/10.1371/journal.pone.0169335.

49. Maher, P. Fisetin acts on multiple pathways to reduce the impact of age and disease on CNS function. Frontiers in bioscience (Scholar edition) 2015, 7, https://doi.org/10.2741/425.

50. Burich, R.A.; Holland, W.S.; Vinall, R.L.; Tepper, C.; DeVere White, R.W.; Mack, P.C. Genistein combined polysaccharide enhances activity of docetaxel, bicalutamide and Src kinase inhibition in androgen-dependent and independent prostate cancer cell lines. BJU international 2008, 102, 1458-1466, https://doi.org/10.1111/j.1464-410X.2008.07826.x.

51. Yuan, L.; Wagatsuma, C.; Yoshida, M.; Miura, T.; Mukoda, T.; Fujii, H.; Sun, B.; Kim, J.H.; Surh, Y.J. Inhibition of human breast cancer growth by GCPTM(genistein combined polysaccharide) in xenogeneic athymic mice: involvement of genistein biotransformation by $\beta$-glucuronidase from tumor tissues. Mutation Research/Fundamental and Molecular Mechanisms of Mutagenesis 2003, 523, 55-62, https://doi.org/10.1016/s0027-5107(02)00321-4.

52. Ramalingam, M.; Kim, H.; Lee, Y.; Lee, Y.I. Phytochemical and pharmacological role of liquiritigenin and isoliquiritigenin from Radix Glycyrrhizae in human health and disease models. Frontiers in aging neuroscience 2018, 10, https://doi.org/10.3389/fnagi.2018.00348.

53. Weis, K.E.; Raetzman, L.T. Isoliquiritigenin exhibits anti-proliferative properties in the pituitary independent of estrogen receptor function. Toxicology and applied pharmacology 2016, 313, 204-214, https://doi.org/10.1016/j.taap.2016.09.027.

54. Yemoa, A.; Gbenou, J.; Affolabi, D.; Moudachirou, M.; Bigot, A.; Anagonou, S.; Portaels, F.; Martin, A.; Quetin-Leclercq, J. Beninese Medicinal Plants as a Source of Antimycobacterial Agents: Bioguided Fractionation and In Vitro Activity of Alkaloids Isolated from Holarrhena floribunda Used in Traditional Treatment of Buruli Ulcer. Biomed Res Int 2015, 2015, https://doi.org/10.1155/2015/835767.

55. Lin, Y.; Shi, R.; Wang, X.; Shen, H.M. Luteolin, a flavonoid with potential for cancer prevention and therapy. Current cancer drug targets 2008, 8, 634-646, https://doi.org/10.2174/156800908786241050.

56. Ahmed, S.; Khan, H.; Fratantonio, D.; Hasan, M.M.; Sharifi, S.; Fathi, N.; Ullah, H.; Rastrelli, L. Apoptosis induced by luteolin in breast cancer: Mechanistic and therapeutic perspectives. Phytomedicine 2019, 59, https://doi.org/10.1016/j.phymed.2019.152883.

57. Weiskirchen, R.; Mahli, A.; Weiskirchen, S.; Hellerbrand, C. The hop constituent xanthohumol exhibits hepatoprotective effects and inhibits the activation of hepatic stellate cells at different levels. Frontiers in physiology 2015, 6, https://doi.org/10.3389/fphys.2015.00140. 
58. Arczewska, M.; Kamiński, D.M.; Gieroba, B.; Gagoś, M. Acid-Base Properties of Xanthohumol: A Computational and Experimental Investigation. Journal of natural products 2017, 80, 3194-3202, https://doi.org/10.1021/acs.jnatprod.7b00530.

59. Hirata, H.; Uto-Kondo, H.; Ogura, M.; Ayaori, M.; Shiotani, K.; Ota, A.; Tsuchiya, Y.; Ikewaki, K. Xanthohumol, a hop-derived prenylated flavonoid, promotes macrophage reverse cholesterol transport. The Journal of nutritional biochemistry 2017, 47, 29-34, https://doi.org/10.1016/j.jnutbio.2017.04.011.

60. Chen, F.; Ma, Y.; Sun, Z.; Zhu, X. Tangeretin inhibits high glucose-induced extracellular matrix accumulation in human glomerular mesangial cells. Biomedicine \& Pharmacotherapy 2018, 102, 10771083, https://doi.org/10.1016/j.biopha.2018.03.169.

61. Zhang, Y.; Xiao, S.; Sun, L.; Ge, Z.; Fang, F.; Zhang, W.; Wang, Y.; Cheng, Y. Rapid screening of bioactive compounds from natural products by integrating 5-channel parallel chromatography coupled with on-line mass spectrometry and microplate based assays. Analytica chimica acta 2013, 777, 49-56, https://doi.org/10.1016/j.aca.2013.03.028.

62. Chhabra, N.; Buzarbaruah, S.; Singh, R.; Kaur, J. Silibinin: A promising anti-neoplastic agent for the future? A critical reappraisal. International Journal of Nutrition, Pharmacology, Neurological Diseases 2013, 3, 206, https://doi.org/10.4103/2231-0738.114836.

63. Abenavoli, L.; Izzo, A.A.; Milić, N.; Cicala, C.; Santini, A.; Capasso, R. Milk thistle (Silybum marianum): A concise overview on its chemistry, pharmacological, and nutraceutical uses in liver diseases. Phytotherapy research : PTR 2018, 32, 2202-2213, https://doi.org/10.1002/ptr.6171.

64. Esmaeil, N.; Anaraki, S.B.; Gharagozloo, M.; Moayedi, B. Silymarin impacts on immune system as an immunomodulator: One key for many locks. International immunopharmacology 2017, 50, 194-201, https://doi.org/10.1016/j.intimp.2017.06.030.

65. Shankar, G.M.; Antony, J.; Anto, R.J. Quercetin and tryptanthrin: two broad spectrum anticancer agents for future chemotherapeutic interventions. In: The enzymes. Volume 37, Elsevier: 2015; pp. 43-72, https://doi.org/10.1016/bs.enz.2015.05.001.

66. Murota, K.; Nakamura, Y.; Uehara, M. Flavonoid metabolism: the interaction of metabolites and gut microbiota. Bioscience, biotechnology, and biochemistry 2018, 82, 600-610, https://doi.org/10.1080/09168451.2018.1444467.

67. Semalty, A.; Semalty, M.; Singh, D.; Rawat, M. Preparation and characterization of phospholipid complexes of naringenin for effective drug delivery. Journal of inclusion phenomena and macrocyclic chemistry 2010 , 67, 253-260, https://doi.org/10.1007/s10847-009-9705-8.

68. Hasanein, P.; Emamjomeh, A. Beneficial Effects of Natural Compounds on Heavy Metal-Induced Hepatotoxicity. In: Dietary Interventions in Liver Disease. Elsevier: 2019; pp. 345-355, https://doi.org/10.1016/B978-0-12-814466-4.00028-8.

69. Lalitha, N.; Sadashivaiah, B.; Ramaprasad, T.R.; Singh, S.A. Anti-hyperglycemic activity of myricetin, through inhibition of DPP-4 and enhanced GLP-1 levels, is attenuated by co-ingestion with lectin-rich protein. PloS one 2020, 15, https://doi.org/10.1371/journal.pone.0231543.

70. Nassiri-Asl, M.; Hosseinzadeh, H. Neuropharmacology effects of saffron (Crocus sativus) and Its active constituents. In: Bioactive Nutraceuticals and Dietary Supplements in Neurological and Brain Disease. Elsevier: 2015; pp. 29-39, https://doi.org/10.1016/B978-0-12-411462-3.00003-5.

71. Xiang, M.; Yang, M.; Zhou, C.; Liu, J.; Li, W.; Qian, Z. Crocetin prevents AGEs-induced vascular endothelial cell apoptosis. Pharmacological research 2006, 54, 268-274, https://doi.org/10.1016/j.phrs.2006.06.010.

72. Ishizuka, F.; Shimazawa, M.; Umigai, N.; Ogishima, H.; Nakamura, S.; Tsuruma, K.; Hara, H. Crocetin, a carotenoid derivative, inhibits retinal ischemic damage in mice. European journal of pharmacology 2013, 703, 1-10, https://doi.org/10.1016/j.ejphar.2013.02.007.

73. Ma, L.; Lin, X.M. Effects of lutein and zeaxanthin on aspects of eye health. Journal of the Science of Food and Agriculture 2010, 90, 2-12, https://doi.org/10.1002/jsfa.3785.

74. Zhao, L.; Sweet, B.V. Lutein and zeaxanthin for macular degeneration. American Journal of Health-System Pharmacy 2008, 65, 1232-1238, https://doi.org/10.2146/ahjp080052.

75. Bramley, P.M. Is lycopene beneficial to human health? Phytochemistry 2000, 54, 233-236, https://doi.org/10.1016/s0031-9422(00)00103-5.

76. Tsai, F.S.; Lin, L.W.; Wu, C.R. Lupeol and Its Role in Chronic Diseases. Advances in experimental medicine and biology 2016, 929, 145-175, https://doi.org/10.1007/978-3-319-41342-6_7.

77. Souza, J.M.; Caldas, A.L.; Tohidi, S.D.; Molina, J.; Souto, A.P.; Fangueiro, R.; Zille, A. Properties and controlled release of chitosan microencapsulated limonene oil. Revista Brasileira de Farmacognosia 2014, 24, 691-698, https://doi.org/10.1016/j.bjp.2014.11.007.

78. Nozaki, H.; Otani, I.; Noyori, R.; Kawanisi, M. Photochemical reactions of trans-anethole. Tetrahedron 1968, 24, 2183-2192, https://doi.org/10.1016/0040-4020(68)88120-7.

79. Matsuda, H.; Ninomiya, K.; Morikawa, T.; Yoshikawa, M. Inhibitory effect and action mechanism of sesquiterpenes from Zedoariae Rhizoma on D-galactosamine/lipopolysaccharide-induced liver injury. Bioorganic \& medicinal chemistry letters 1998, 8, 339-344, https://doi.org/10.1016/s0960-894x(98)000213 . 
80. Saeed, A.; Larik, F.A. Current Topics in Herbal Medicine with Applications in Cardiovascular Diseases. Cardiovascular Diseases 2017, 1, https://doi.org/10.2174/9781681084893117010008.

81. Johnson, J.J. Carnosol: a promising anti-cancer and anti-inflammatory agent. Cancer letters 2011, 305, 1-7, https://doi.org/10.1016/j.canlet.2011.02.005.

82. Loussouarn, M.; Krieger-Liszkay, A.; Svilar, L.; Bily, A.; Birtić, S.; Havaux, M. Carnosic acid and carnosol, two major antioxidants of rosemary, act through different mechanisms. Plant physiology 2017, 175, 13811394, https://doi.org/10.1104/pp.17.01183.

83. Awad, A.; Chinnam, M.; Fink, C.; Bradford, P. $\beta$-Sitosterol activates Fas signaling in human breast cancer cells. Phytomedicine 2007, 14, 747-754, https://doi.org/10.1016/j.phymed.2007.01.003.

84. Woyengo, T.; Ramprasath, V.; Jones, P. Anticancer effects of phytosterols. European journal of clinical nutrition 2009, 63, 813-820, https://doi.org/10.1038/ejcn.2009.29.

85. Zhang, P.; Zhu, K.L.; Zhang, J.; Li, Y.; Zhang, H.; Wang, Y. Purification of flavonoids from mulberry leaves via high-speed counter-current chromatography. Processes 2019, 7, https://doi.org/10.3390/pr7020091.

86. Aslam, M.S.; Ahmad, M.S.; Mamat, A.S. Phytochemical Evaluation of Polyherbal Formulation of Clinacanthus nutans and Elephantopus scaber to Identify Flavonoids. Pharmacognosy Journal 2016, 8, https://doi.org/10.5530/pj.2016.6.4.

87. Li, H.; Shi, J.; Li, Y.; Wang, C.; Hou, G.; Cong, W.; Zhao, F. Purification of spinosin from Ziziphi Spinosae Semen using macroporous resins followed by preparative high-performance liquid chromatography. Journal of separation science 2019, 42, 3134-3140, https://doi.org/10.1002/jssc.201900433.

88. Al-Huqail, A.A.; Behiry, S.I.; Salem, M.Z.; Ali, H.M.; Siddiqui, M.H.; Salem, A.Z. Antifungal, antibacterial, and antioxidant activities of Acacia saligna (Labill.) HL Wendl. flower extract: HPLC analysis of phenolic and flavonoid compounds. Molecules 2019, 24, https://doi.org/10.3390/molecules24040700.

89. Cragg, G.M.; Newman, D.J. Natural products: a continuing source of novel drug leads. Biochimica et Biophysica Acta (BBA)-General Subjects 2013, 1830, 3670-3695, https://doi.org/10.1016/j.bbagen.2013.02.008.

90. Falcone Ferreyra, M.L.; Rius, S.; Casati, P. Flavonoids: biosynthesis, biological functions, and biotechnological applications. Frontiers in plant science 2012, 3, https://doi.org/10.3389/fpls.2012.00222.

91. Koes, R.E.; Quattrocchio, F.; Mol, J.N. The flavonoid biosynthetic pathway in plants: function and evolution. BioEssays 1994, 16, 123-132, https://doi.org/10.1002/bies.950160209.

92. Quattrocchio, F.; Baudry, A.; Lepiniec, L.; Grotewold, E. The regulation of flavonoid biosynthesis. In: The science of flavonoids. Springer: 2006; pp. 97-122, https://doi.org/10.1007/978-0-387-28822-2_4.

93. Yu, C.P.; Shia, C.S.; Tsai, S.Y.; Hou, Y.C. Pharmacokinetics and relative bioavailability of flavonoids between two dosage forms of gegen-qinlian-tang in rats. Evidence-Based Complementary and Alternative Medicine 2012, 2012, https://doi.org/10.1155/2012/308018.

94. Cai, X.; Fang, Z.; Dou, J.; Yu, A.; Zhai, G. Bioavailability of quercetin: problems and promises. Current medicinal chemistry 2013, 20, 2572-2582, https://doi.org/10.2174/09298673113209990120.

95. Mauludin, R.; Müller, R.H.; Keck, C.M. Kinetic solubility and dissolution velocity of rutin nanocrystals. european journal of pharmaceutical sciences 2009, 36, 502-510, https://doi.org/10.1016/j.ejps.2008.12.002.

96. Mandalari, G.; Tomaino, A.; Rich, G.; Curto, R.L.; Arcoraci, T.; Martorana, M.; Bisignano, C.; Saija, A.; Parker, M.; Waldron, K. Polyphenol and nutrient release from skin of almonds during simulated human digestion. Food chemistry 2010, 122, 1083-1088, https://doi.org/10.3390/antiox8040095.

97. Gee, J.M.; DuPont, M.S.; Day, A.J.; Plumb, G.W.; Williamson, G.; Johnson, I.T. Intestinal transport of quercetin glycosides in rats involves both deglycosylation and interaction with the hexose transport pathway. The Journal of nutrition 2000, 130, 2765-2771, https://doi.org/10.1093/jn/130.11.2765.

98. Spencer, J.P. Metabolism of tea flavonoids in the gastrointestinal tract. The Journal of nutrition 2003, 133, 3255S-3261S, https://doi.org/10.1093/jn/133.10.3255S.

99. Heim, K.E.; Tagliaferro, A.R.; Bobilya, D.J. Flavonoid antioxidants: chemistry, metabolism and structureactivity relationships. The Journal of nutritional biochemistry 2002, 13, 572-584, https://doi.org/10.1016/s0955-2863(02)00208-5.

100. Aura, A.M.; Martin-Lopez, P.; O’Leary, K.A.; Williamson, G.; Oksman-Caldentey, K.M.; Poutanen, K.; Santos-Buelga, C. In vitro metabolism of anthocyanins by human gut microflora. European journal of nutrition 2005, 44, 133-142, https://doi.org/10.1007/s00394-004-0502-2.

101. Gonthier, M.P.; Verny, M.A.; Besson, C.; Rémésy, C.; Scalbert, A. Chlorogenic acid bioavailability largely depends on its metabolism by the gut microflora in rats. The Journal of nutrition 2003, 133, 1853-1859, https://doi.org/10.1093/jn/133.6.1853.

102. Zhu, H.-J.; Brinda, B.J.; Chavin, K.D.; Bernstein, H.J.; Patrick, K.S.; Markowitz, J.S. An assessment of pharmacokinetics and antioxidant activity of free silymarin flavonolignans in healthy volunteers: a dose escalation study. Drug Metabolism and Disposition 2013, 41, 1679-1685, https://doi.org/10.1124/dmd.113.052423.

103. Spencer, J.P.; Schroeter, H.; Rechner, A.R.; Rice-Evans, C. Bioavailability of flavan-3-ols and procyanidins: gastrointestinal tract influences and their relevance to bioactive forms in vivo. Antioxidants and redox signaling 2001, 3, 1023-1039, https://doi.org/10.1089/152308601317203558. 
104. Cruz, B.G.; Dos Santos, H.S.; Bandeira, P.N.; Rodrigues, T.H.S.; Matos, M.G.C.; Nascimento, M.F.; de Carvalho, G.G.; Braz-Filho, R.; Teixeira, A.M.; Tintino, S.R. Evaluation of antibacterial and enhancement of antibiotic action by of flavonoid kaempferol 7-O- $\beta$-D-(6"-O-cumaroyl)-glucopyranoside isolated from Croton piauhiensis Müll. Microbial Pathogenesis 2020,143 , https://doi.org/10.1016/j.micpath.2020.104144.

105. Gawande, S.; Kale, A.; Kotwal, S. Effect of nutrient mixture and black grapes on the pharmacokinetics of orally administered (-) epigallocatechin-3-gallate from green tea extract: a human study. Phytotherapy Research: An International Journal Devoted to Pharmacological and Toxicological Evaluation of Natural Product Derivatives 2008, 22, 802-808, https://doi.org/10.1002/ptr.2372.

106. Fresco, P.; Borges, F.; Diniz, C.; Marques, M. New insights on the anticancer properties of dietary polyphenols. Medicinal research reviews 2006, 26, 747-766, https://doi.org/10.1002/med.20060.

107. Kř́̌žková, J.; Burdová, K.; Stiborová, M.; Křen, V.; Hodek, P. The effects of selected flavonoids on cytochromes $\mathrm{P} 450$ in rat liver and small intestine. Interdisciplinary toxicology 2009, 2, 201-204, https://doi.org/10.2478/v10102-009-0018-y.

108. Xiao, J.; Kai, G. A review of dietary polyphenol-plasma protein interactions: characterization, influence on the bioactivity, and structure-affinity relationship. Critical reviews in food science and nutrition 2012, 52, 85-101, https://doi.org/10.1080/10408398.2010.499017.

109. Alfarouk, K.O.; Stock, C.-M.; Taylor, S.; Walsh, M.; Muddathir, A.K.; Verduzco, D.; Bashir, A.H.; Mohammed, O.Y.; Elhassan, G.O.; Harguindey, S. Resistance to cancer chemotherapy: failure in drug response from ADME to P-gp. Cancer cell international 2015, 15, https://doi.org/10.1186/s12935-0150221-1.

110. Sun, Y.L.; Patel, A.; Kumar, P.; Chen, Z.S. Role of ABC transporters in cancer chemotherapy. Chinese journal of cancer 2012, 31.

111. Assaraf, Y.G.; Brozovic, A.; Gonçalves, A.C.; Jurkovicova, D.; Linē, A.; Machuqueiro, M.; Saponara, S.; Sarmento-Ribeiro, A.B.; Xavier, C.P.; Vasconcelos, M.H. The multi-factorial nature of clinical multidrug resistance in cancer. Drug Resistance Updates 2019, 46, https://doi.org/10.1016/j.drup.2019.100645.

112. Chedik, L.; Bruyere, A.; Fardel, O. Interactions of organophosphorus pesticides with solute carrier (SLC) drug transporters. Xenobiotica 2019, 49, 363-374, https://doi.org/10.1080/00498254.2018.1442030.

113. Rice, A.J.; Park, A.; Pinkett, H.W. Diversity in ABC transporters: type I, II and III importers. Critical reviews in biochemistry and molecular biology 2014, 49, 426-437, https://doi.org/10.3109/10409238.2014.953626.

114. Chen, Z.; Shi, T.; Zhang, L.; Zhu, P.; Deng, M.; Huang, C.; Hu, T.; Jiang, L.; Li, J. Mammalian drug efflux transporters of the ATP binding cassette $(\mathrm{ABC})$ family in multidrug resistance: A review of the past decade. Cancer letters 2016, 370, 153-164, https://doi.org/10.1016/j.canlet.2015.10.010.

115. Klappe, K.; Hummel, I.; Hoekstra, D.; Kok, J.W. Lipid dependence of ABC transporter localization and function. Chemistry and Physics of Lipids 2009, 161, 57-64, https://doi.org/10.1016/j.chemphyslip.2009.07.004.

116. Russel, F.G. Transporters: importance in drug absorption, distribution, and removal. In: Enzyme-and transporter-based drug-drug interactions. Springer: 2010; pp. 27-49, https://doi.org/10.1007/978-1-44190840-7_2.

117. Alvarez, A.I.; Real, R.; Pérez, M.; Mendoza, G.; Prieto, J.G.; Merino, G. Modulation of the activity of ABC transporters (P-glycoprotein, MRP2, BCRP) by flavonoids and drug response. Journal of pharmaceutical sciences 2010, 99, 598-617, https://doi.org/10.1002/jps.21851.

118. Ravisankar, S.; Agah, S.; Kim, H.; Talcott, S.; Wu, C.; Awika, J. Combined cereal and pulse flavonoids show enhanced bioavailability by downregulating phase II metabolism and ABC membrane transporter function in Caco-2 model. Food chemistry 2019, 279, 88-97, https://doi.org/10.1016/j.foodchem.2018.12.006.

119. Gatouillat, G.; Magid, A.A.; Bertin, E.; Morjani, H.; Lavaud, C.; Madoulet, C. Medicarpin and millepurpan, two flavonoids isolated from Medicago sativa, induce apoptosis and overcome multidrug resistance in leukemia P388 cells. Phytomedicine 2015, 22, 1186-1194, https://doi.org/10.1016/j.phymed.2015.09.005.

120. Dash, R.P.; Ellendula, B.; Agarwal, M.; Nivsarkar, M. Increased intestinal P-glycoprotein expression and activity with progression of diabetes and its modulation by epigallocatechin-3-gallate: Evidence from pharmacokinetic studies. European journal of pharmacology 2015, 767, 67-76, https://doi.org/10.1016/j.ejphar.2015.10.009.

121. Cano, A.; Ettcheto, M.; Chang, J.-H.; Barroso, E.; Espina, M.; Kühne, B.A.; Barenys, M.; Auladell, C.; Folch, J.; Souto, E.B. Dual-drug loaded nanoparticles of Epigallocatechin-3-gallate (EGCG)/Ascorbic acid enhance therapeutic efficacy of EGCG in a APPswe/PS1dE9 Alzheimer's disease mice model. Journal of Controlled Release 2019, 301, 62-75, https://doi.org/10.1016/j.jconrel.2019.03.010.

122. Yang, Z.; Zhu, M.Z.; Zhang, Y.B.; Wen, B.B.; An, H.M.; Ou, X.C.; Xiong, Y.F.; Lin, H.Y.; Liu, Z.H.; Huang, J.A. Coadministration of epigallocatechin-3-gallate (EGCG) and caffeine in low dose ameliorates obesity and nonalcoholic fatty liver disease in obese rats. Phytotherapy Research 2019, 33, 1019-1026, https://doi.org/10.1002/ptr.6295. 
123. Mori, T.; Koyama, N.; Tan, J.; Segawa, T.; Maeda, M.; Town, T. Combined treatment with the phenolics (-)-epigallocatechin-3-gallate and ferulic acid improves cognition and reduces Alzheimer-like pathology in mice. Journal of Biological Chemistry 2019, 294, 2714-2731, https://doi.org/10.1074/jbc.RA118.004280.

124. Li, Y.; Paxton, J.W. The effects of flavonoids on the ABC transporters: consequences for the pharmacokinetics of substrate drugs. Expert opinion on drug metabolism \& toxicology 2013, 9, 267-285, https://doi.org/10.1517/17425255.2013.749858.

125. Zeng, M.; Sun, R.; Basu, S.; Ma, Y.; Ge, S.; Yin, T.; Gao, S.; Zhang, J.; Hu, M. Disposition of flavonoids via recycling: Direct biliary excretion of enterically or extrahepatically derived flavonoid glucuronides. Molecular nutrition \& food research 2016, 60, 1006-1019, https://doi.org/10.1002/mnfr.201500692.

126. Guinane, C.M.; Cotter, P.D. Role of the gut microbiota in health and chronic gastrointestinal disease: understanding a hidden metabolic organ. Therapeutic advances in gastroenterology 2013, 6, 295-308, https://doi.org/10.1177/1756283X13482996.

127. Sehrawat, N.; Yadav, M.; Singh, M.; Kumar, V.; Sharma, V.R.; Sharma, A.K. Probiotics in microbiome ecological balance providing a therapeutic window against cancer. In: Proceedings of Semin Cancer Biol. 2020, In press, https://doi.org/10.1016/j.semcancer.2020.06.009.

128. Lu, K.; Mahbub, R.; Fox, J.G. Xenobiotics: interaction with the intestinal microflora. ILAR journal 2015, 56, 218-227, https://doi.org/10.1093/ilar/ilv018.

129. Laparra, J.M.; Sanz, Y. Interactions of gut microbiota with functional food components and nutraceuticals. Pharmacological research 2010, 61, 219-225, https://doi.org/10.1016/j.phrs.2009.11.001.

130. Oak, S.J.; Jha, R. The effects of probiotics in lactose intolerance: a systematic review. Critical reviews in food science and nutrition 2019, 59, 1675-1683, https://doi.org/10.1080/10408398.2018.1425977.

131. Lin, W.; Wang, W.; Yang, H.; Wang, D.; Ling, W. Influence of intestinal microbiota on the catabolism of flavonoids in mice. Journal of food science 2016, 81, H3026-H3034, https://doi.org/10.1111/17503841.13544.

132. Ozdal, T.; Sela, D.A.; Xiao, J.; Boyacioglu, D.; Chen, F.; Capanoglu, E. The reciprocal interactions between polyphenols and gut microbiota and effects on bioaccessibility. Nutrients 2016, 8, https://doi.org/10.3390/nu8020078.

133. Nurmi, T.; Mursu, J.; Heinonen, M.; Nurmi, A.; Hiltunen, R.; Voutilainen, S. Metabolism of berry anthocyanins to phenolic acids in humans. Journal of agricultural and food chemistry 2009, 57, 2274-2281, https://doi.org/10.1021/jf8035116.

134. Simons, A.L.; Renouf, M.; Hendrich, S.; Murphy, P.A. Human gut microbial degradation of flavonoids: structure-function relationships. Journal of agricultural and food chemistry 2005, 53, 4258-4263, https://doi.org/10.1021/jf0500177.

135. Singh, R.K.; Chang, H.W.; Yan, D.; Lee, K.M.; Ucmak, D.; Wong, K.; Abrouk, M.; Farahnik, B.; Nakamura, M.; Zhu, T.H.; Bhutani, T.; Liao, W. Influence of diet on the gut microbiome and implications for human health. Journal of translational medicine 2017, 15, https://doi.org/10.1186/s12967-017-1175-y.

136. Fotschki, B.; Juśkiewicz, J.; Sójka, M.; Jurgoński, A.; Zduńczyk, Z. Ellagitannins and flavan-3-ols from raspberry pomace modulate caecal fermentation processes and plasma lipid parameters in rats. Molecules 2015, 20, 22848-22862, https://doi.org/10.3390/molecules201219878.

137. Esposito, D.; Damsud, T.; Wilson, M.; Grace, M.H.; Strauch, R.; Li, X.; Lila, M.A.; Komarnytsky, S. Black currant anthocyanins attenuate weight gain and improve glucose metabolism in diet-induced obese mice with intact, but not disrupted, gut microbiome. Journal of agricultural and food chemistry 2015, 63, 6172-6180, https://doi.org/10.1021/acs.jafc.5b00963.

138. Liu, Y.; Wang, H.; Cai, X. Optimization of the extraction of total flavonoids from Scutellaria baicalensis Georgi using the response surface methodology. Journal of food science and technology 2015, 52, 23362343, https://doi.org/10.1007/s13197-014-1275-0.

139. Wang, X.; Wu, Y.; Chen, G.; Yue, W.; Liang, Q.; Wu, Q. Optimisation of ultrasound assisted extraction of phenolic compounds from Sparganii rhizoma with response surface methodology. Ultrasonics sonochemistry 2013, 20, 846-854, https://doi.org/10.1016/j.ultsonch.2012.11.007.

140. Ram, S.; Gahlot, K.S.V.; Sheikh, I.; Sankhyan, A.; Aggarwal, D.; Sharma, A.K. Anti-cancer potential of natural products: recent trends, scope and relevance. Letters in Applied NanoBioScience 2020, 9, 902-907.

141. Zhu, Y.; Liu, Y.; Zhan, Y.; Liu, L.; Xu, Y.; Xu, T.; Liu, T. Preparative isolation and purification of five flavonoid glycosides and one benzophenone galloyl glycoside from Psidium guajava by high-speed countercurrent chromatography (HSCCC). Molecules 2013, 18, 15648-15661, https://doi.org/10.3390/molecules181215648.

142. Khan, N.; Mukhtar, H. Tea polyphenols for health promotion. Life sciences 2007, 81, 519-533, https://doi.org/10.1016/j.lfs.2007.06.011.

143. Kurepa, J.; Nakabayashi, R.; Paunesku, T.; Suzuki, M.; Saito, K.; Woloschak, G.E.; Smalle, J.A. Direct isolation of flavonoids from plants using ultra-small anatase TiO 2 nanoparticles. The Plant Journal 2014, 77, 443-453, https://doi.org/10.1111/tpj.12361.

144. Wang, J.; Zhao, Y.M.; Guo, C.Y.; Zhang, S.M.; Liu, C.L.; Zhang, D.S.; Bai, X.M. Ultrasound-assisted extraction of total flavonoids from Inula helenium. Pharmacognosy magazine 2012, 8, https://doi.org/10.4103/0973-1296.96581. 
145. Zheng, L.L.; Wang, D.; Li, Y.Y.; Peng, H.Y.; Yuan, M.Y.; Gao, F. Ultrasound-assisted extraction of total flavonoids from Aconitum gymnandrum. Pharmacognosy magazine 2014, 10, 141-146, https://doi.org/10.4103/0973-1296.127364.

146. Wu, J.; Du, G.; Zhou, J.; Chen, J. Systems metabolic engineering of microorganisms to achieve large-scale production of flavonoid scaffolds. Journal of biotechnology 2014, 188, 72-80, https://doi.org/10.1016/j.jbiotec.2014.08.016.

147. Thilakarathna, S.H.; Rupasinghe, H. Flavonoid bioavailability and attempts for bioavailability enhancement. Nutrients 2013, 5, 3367-3387, https://doi.org/10.3390/nu5093367.

148. Olthof, M.R.; Hollman, P.C.; Vree, T.B.; Katan, M.B. Bioavailabilities of quercetin-3-glucoside and quercetin-4'-glucoside do not differ in humans. The Journal of nutrition 2000, 130, 1200-1203, https://doi.org/10.1093/jn/130.5.1200.

149. Peterson, B.; Weyers, M.; Steenekamp, J.H.; Steyn, J.D.; Gouws, C.; Hamman, J.H. Drug Bioavailability Enhancing Agents of Natural Origin (Bioenhancers) that Modulate Drug Membrane Permeation and PreSystemic Metabolism. Pharmaceutics 2019, 11, https://doi.org/10.3390/pharmaceutics11010033.

150. Rinwa, P.; Kumar, A. Quercetin along with piperine prevents cognitive dysfunction, oxidative stress and neuro-inflammation associated with mouse model of chronic unpredictable stress. Archives of pharmacal research 2017, 40, 1166-1175, https://doi.org/10.1007/s12272-013-0205-4.

151. Lambert, J.D.; Hong, J.; Kim, D.H.; Mishin, V.M.; Yang, C.S. Piperine enhances the bioavailability of the tea polyphenol (-)-epigallocatechin-3-gallate in mice. The Journal of nutrition 2004, 134, 1948-1952, https://doi.org/10.1093/jn/134.8.1948.

152. Gao, S.; Hu, M. Bioavailability challenges associated with development of anti-cancer phenolics. Mini reviews in medicinal chemistry 2010, 10, 550-567, https://doi.org/10.2174/138955710791384081.

153. Althagafy, H.S.; Graf, T.N.; Sy-Cordero, A.A.; Gufford, B.T.; Paine, M.F.; Wagoner, J.; Polyak, S.J.; Croatt, M.P.; Oberlies, N.H. Semisynthesis, cytotoxicity, antiviral activity, and drug interaction liability of 7-Omethylated analogues of flavonolignans from milk thistle. Bioorganic \& medicinal chemistry 2013, 21, 3919-3926, https://doi.org/10.1016/j.bmc.2013.04.017.

154. Grande, F.; Parisi, O.I.; Mordocco, R.A.; Rocca, C.; Puoci, F.; Scrivano, L.; Quintieri, A.M.; Cantafio, P.; Ferla, S.; Brancale, A. Quercetin derivatives as novel antihypertensive agents: Synthesis and physiological characterization. European Journal of Pharmaceutical Sciences 2016, 82, 161-170, https://doi.org/10.1016/j.ejps.2015.11.021.

155. Kim, M.K.; Park, K.S.; Lee, C.; Park, H.R.; Choo, H.; Chong, Y. Enhanced stability and intracellular accumulation of quercetin by protection of the chemically or metabolically susceptible hydroxyl groups with a pivaloxymethyl (POM) promoiety. Journal of medicinal chemistry 2010, 53, 8597-8607, https://doi.org/10.1021/jm101252m.

156. Macedo, A.S.; Quelhas, S.; Silva, A.M.; Souto, E.B. Nanoemulsions for delivery of flavonoids: formulation and in vitro release of rutin as model drug. Pharmaceutical development and technology 2014, 19, 677-680, https://doi.org/10.3109/10837450.2013.823989.

157. Yi, T.; Liu, C.; Zhang, J.; Wang, F.; Wang, J.; Zhang, J. A new drug nanocrystal self-stabilized Pickering emulsion for oral delivery of silybin. European Journal of Pharmaceutical Sciences 2017, 96, 420-427, https://doi.org/10.1016/j.ejps.2016.08.047.

158. Zhu, Y.; Wang, M.; Zhang, Y.; Zeng, J.; Omari-Siaw, E.; Yu, J.; Xu, X. In vitro release and bioavailability of silybin from micelle-templated porous calcium phosphate microparticles. AAPS PharmSciTech 2016, 17, 1232-1239, https://doi.org/10.1208/s12249-015-0460-4.

159. Penalva, R.; González-Navarro, C.J.; Gamazo, C.; Esparza, I.; Irache, J.M. Zein nanoparticles for oral delivery of quercetin: Pharmacokinetic studies and preventive anti-inflammatory effects in a mouse model of endotoxemia. Nanomedicine: Nanotechnology, Biology and Medicine 2017, 13, 103-110, https://doi.org/10.1016/j.nano.2016.08.033.

160. Filippi, A.; Petrussa, E.; Rajcevic, U.; Čurin Šerbec, V.; Passamonti, S.; Renzone, G.; Scaloni, A.; Zancani, M.; Vianello, A.; Braidot, E. Flavonoid Interaction with a Chitinase from Grape Berry Skin: Protein Identification and Modulation of the Enzymatic Activity. Molecules 2016, 21, https://doi.org/10.3390/molecules21101300.

161. Arroyo-Maya, I.J.; Campos-Terán, J.; Hernández-Arana, A.; McClements, D.J. Characterization of flavonoid-protein interactions using fluorescence spectroscopy: Binding of pelargonidin to dairy proteins. Food chemistry 2016, 213, 431-439, https://doi.org/10.1016/j.foodchem.2016.06.105.

162. Cui, X.; Jin, Y.; Hofseth, A.B.; Pena, E.; Habiger, J.; Chumanevich, A.; Poudyal, D.; Nagarkatti, M.; Nagarkatti, P.S.; Singh, U.P. Resveratrol suppresses colitis and colon cancer associated with colitis. Cancer prevention research 2010, 1940-6207, https://doi.org/10.1158/1940-6207.CAPR-09-0117.

163. Sharma, V.R.; Mishra, N.S.D.; Sharma, A.K.; Batra, N. New and potential therapies for the treatment of Breast Cnacer: An update for oncologists. Current Trends in Biotechnology and Chemical Research 2016, $6,1-2$.

164. Bravo, L. Polyphenols: chemistry, dietary sources, metabolism, and nutritional significance. Nutrition reviews 1998, 56, 317-333, https://doi.org/10.1111/j.1753-4887.1998.tb01670.x. 
165. Manson, M.M. Cancer prevention-the potential for diet to modulate molecular signalling. Trends in molecular medicine 2003, 9, 11-18, https://doi.org/10.1016/s1471-4914(02)00002-3.

166. Surh, Y.J. Cancer chemoprevention with dietary phytochemicals. Nature Reviews Cancer 2003, 3, https://doi.org/10.1038/nrc1189.

167. Knekt, P.; Järvinen, R.; Seppänen, R.; Heliövaara, M.; Teppo, L.; Pukkala, E.; Aromaa, A. Dietary flavonoids and the risk of lung cancer and other malignant neoplasms. American journal of epidemiology 1997, 146, 223-230, https://doi.org/10.1093/oxfordjournals.aje.a009257.

168. De Stefani, E.; Ronco, A.; Mendilaharsu, M.; Deneo-Pellegrini, H. Diet and risk of cancer of the upper aerodigestive tract-II. Nutrients. Oral oncology 1999, 35, 22-26, https://doi.org/10.1016/s13688375(98)00061-x.

169. Le Marchand, L.; Murphy, S.P.; Hankin, J.H.; Wilkens, L.R.; Kolonel, L.N. Intake of flavonoids and lung cancer. Journal of the National Cancer Institute 2000, 92, 154-160, https://doi.org/10.1093/jnci/92.2.154.

170. Knekt, P.; Kumpulainen, J.; Järvinen, R.; Rissanen, H.; Heliövaara, M.; Reunanen, A.; Hakulinen, T.; Aromaa, A. Flavonoid intake and risk of chronic diseases. The American journal of clinical nutrition 2002, 76, 560-568, https://doi.org/10.1093/ajcn/76.3.560.

171. Garcia-Closas, R.; Gonzalez, C.A.; Agudo, A.; Riboli, E. Intake of specific carotenoids and flavonoids and the risk of gastric cancer in Spain. Cancer Causes \& Control 1999, 10, 7175, https://doi.org/10.1023/a:1008867108960.

172. Arts, I.C.; Jacobs, D.R.; Gross, M.; Harnack, L.J.; Folsom, A.R. Dietary catechins and cancer incidence among postmenopausal women: the Iowa Women's Health Study (United States). Cancer Causes \& Control 2002, 13, 373-382, https://doi.org/10.1023/a:1015290131096.

173. Su, L.J.; Arab, L. Tea consumption and the reduced risk of colon cancer-results from a national prospective cohort study. Public health nutrition 2002, 5, 419-425, https://doi.org/10.1079/phn2001314.

174. Imai, K.; Suga, K.; Nakachi, K. Cancer-preventive effects of drinking green tea among a Japanese population. Preventive medicine 1997, 26, 769-775, https://doi.org/10.1006/pmed.1997.0242.

175. Nakachi, K.; Suemasu, K.; Suga, K.; Takeo, T.; Imai, K.; Higashi, Y. Influence of drinking green tea on breast cancer malignancy among Japanese patients. Japanese Journal of Cancer Research 1998, 89, 254261, https://doi.org/10.1111/j.1349-7006.1998.tb00556.X.

176. Tsubono, Y.; Nishino, Y.; Komatsu, S.; Hsieh, C.C.; Kanemura, S.; Tsuji, I.; Nakatsuka, H.; Fukao, A.; Satoh, H.; Hisamichi, S. Green tea and the risk of gastric cancer in Japan. New England Journal of Medicine 2001, 344, 632-636, https://doi.org/10.1056/NEJM200103013440903.

177. Goldbohm, R.A.; Hertog, M.G.; Brants, H.A.; van Poppel, G.; van den Brandt, P.A. Consumption of black tea and cancer risk: a prospective cohort study. JNCI: Journal of the National Cancer Institute 1996, 88, 93100, https://doi.org/10.1093/jnci/88.2.93.

178. Wakai, K.; Ohno, Y.; Genka, K.; Ohmine, K.; Kawamura, T.; Tamakoshi, A.; Lin, Y.; Nakayama, T.; Aoki, K.; Fukuma, S. Risk modification in lung cancer by a dietary intake of preserved foods and soyfoods: findings from a case-control study in Okinawa, Japan. Lung Cancer 1999, 25, 147-159, https://doi.org/10.1016/s0169-5002(99)00051-3.

179. Key, T.; Sharp, G.; Appleby, P.; Beral, V.; Goodman, M.; Soda, M.; Mabuchi, K. Soya foods and breast cancer risk: a prospective study in Hiroshima and Nagasaki, Japan. British journal of cancer 1999, 81, 1248, https://doi.org/10.1038/sj.bjc.6690837.

180. Yang, C.S.; Maliakal, P.; Meng, X. Inhibition of carcinogenesis by tea. Annual review of pharmacology and toxicology 2002, 42, 25-54, https://doi.org/10.1146/annurev.pharmtox.42.082101.154309.

181. Isemura, M. Catechin in Human Health and Disease. Molecules 2019, 24, https://doi.org/10.3390/molecules24030528.

182. Dontas, I.A.; Lambrou, G.I.J.A.o.R.H. The impact of translational studies in the current management of osteoporosis. 2019, 2019, https://doi.org/10.21037/arh.2019.03.01.

183. Liao, S.; Tang, Y.; Chu, C.; Lu, W.; Baligen, B.; Man, Y.; Qu, Y. Application of Green Tea Extracts Epigallocatechin-3-gallate in Dental Materials: Recent Progress and Perspectives. Journal of Biomedical Materials Research Part A 2020, 2020, https://doi.org/10.1002/jbm.a.36991.

184. Imran, M.; Rauf, A.; Shah, Z.A.; Saeed, F.; Imran, A.; Arshad, M.U.; Ahmad, B.; Bawazeer, S.; Atif, M.; Peters, D.G. Chemo-preventive and therapeutic effect of the dietary flavonoid kaempferol: A comprehensive review. Phytotherapy Research 2019, 33, 263-275, https://doi.org/10.1002/ptr.6227.

185. Xing, L.; Zhang, H.; Qi, R.; Tsao, R.; Mine, Y. Recent Advances in the Understanding of the Health Benefits and Molecular Mechanisms Associated with Green Tea Polyphenols. Journal of agricultural and food chemistry 2019, 67, 1029-1043, https://doi.org/10.1021/acs.jafc.8b06146.

186. Liu, J.; Xing, J.; Fei, Y. Green tea (Camellia sinensis) and cancer prevention: a systematic review of randomized trials and epidemiological studies. Chinese medicine 2008, 3, https://doi.org/10.1186/17498546-3-12.

187. Bushman, J.L. Green tea and cancer in humans: a review of the literature. Nutrition and cancer 1998, 31 , 151-159, https://doi.org/10.1080/01635589809514697. 
188. Ruchi Sharma, V.; Kumar Gupta, G.; K Sharma, A.; Batra, N.; K Sharma, D.; Joshi, A.; Sharma, K.A. PI3K/Akt/mTOR intracellular pathway and breast cancer: factors, mechanism and regulation. Current pharmaceutical design 2017, 23, 1633-1638, https://doi.org/10.2174/1381612823666161116125218.

189. Rossi, M.; Strikoudi, P.; Spei, M.E.; Parpinel, M.; Serraino, D.; Montella, M.; Libra, M.; La Vecchia, C.; Rosato, V. Flavonoids and bladder cancer risk. Cancer Causes \& Control 2019, 30, 527-535, https://doi.org/10.1007/s10552-019-01158-2.

190. Islami, F.; Boffetta, P.; Ren, J.S.; Pedoeim, L.; Khatib, D.; Kamangar, F. High-temperature beverages and foods and esophageal cancer risk-A systematic review. International journal of cancer 2009, 125, 491524, https://doi.org/10.1002/ijc.24445.

191. Ren, J.; Freedman, N.; Kamangar, F.; Dawsey, S.; Hollenbeck, A.; Schatzkin, A.; Abnet, C. Tea, coffee, carbonated soft drinks and upper gastrointestinal tract cancer risk in a large United States prospective cohort study. European Journal of Cancer 2010, 46, 1873-1881, https://doi.org/10.1016/j.ejca.2010.03.025.

192. Adhami, V.M.; Mukhtar, H. Anti-oxidants from green tea and pomegranate for chemoprevention of prostate cancer. Molecular biotechnology 2007, 37, 52-57, https://doi.org/10.1007/s12033-007-0047-8.

193. Syed, D.N.; Khan, N.; Afaq, F.; Mukhtar, H. Chemoprevention of prostate cancer through dietary agents: progress and promise. Cancer Epidemiology and Prevention Biomarkers 2007, 16, 2193-2203, https://doi.org/10.1158/1055-9965.EPI-06-0942.

194. Peto, J. Cancer epidemiology in the last century and the next decade. Nature 2001, 411, https://doi.org/10.1038/35077256.

195. Siddiqui, I.A.; Afaq, F.; Adhami, V.M.; Mukhtar, H. Prevention of prostate cancer through custom tailoring of chemopreventive regimen. Chemico-biological interactions 2008, 171, 122-132, https://doi.org/10.1016/j.cbi.2007.03.001.

196. Doll, R. An overview of the epidemiological evidence linking diet and cancer. Proceedings of the Nutrition Society 1990, 49, 119-131, https://doi.org/10.1079/pns19900018.

197. Zou, C.; Liu, H.; Feugang, J.M.; Hao, Z.; Chow, H.S.; Garcia, F. Green tea compound in chemoprevention of cervical cancer. International journal of gynecological cancer: official journal of the International Gynecological Cancer Society 2010, 20, https://doi.org/10.1111/IGC.0b013e3181c7ca5c.

198. Imran, M.; Rauf, A.; Abu-Izneid, T.; Nadeem, M.; Shariati, M.A.; Khan, I.A.; Imran, A.; Orhan, I.E.; Rizwan, M.; Atif, M., et al. Luteolin, a flavonoid, as an anticancer agent: A review. Biomedicine \& pharmacotherapy=Biomedecine \& pharmacotherapie 2019, 112, https://doi.org/10.1016/j.biopha.2019.108612.

199. Luo, J.; Inoue, M.; Iwasaki, M.; Sasazuki, S.; Otani, T.; Ye, W.; Tsugane, S.; Group, J.S. Green tea and coffee intake and risk of pancreatic cancer in a large-scale, population-based cohort study in Japan (JPHC study). European Journal of Cancer Prevention 2007, 16, 542-548, https://doi.org/10.1097/CEJ.0b013e32809b4d30.

200. Genkinger, J.M.; Li, R.; Spiegelman, D.; Anderson, K.E.; Albanes, D.; Bergkvist, L.; Bernstein, L.; Black, A.; Van Den Brandt, P.A.; English, D.R. Coffee, tea, and sugar-sweetened carbonated soft drink intake and pancreatic cancer risk: a pooled analysis of 14 cohort studies. Cancer Epidemiology and Prevention Biomarkers 2012, 21, 305-318, https://doi.org/10.1158/1055-9965.EPI-11-0945-T.

201. Yang, G.Y.; Wang, Z.Y.; Kim, S.; Liao, J.; Seril, D.N.; Chen, X.; Smith, T.J.; Yang, C.S. Characterization of early pulmonary hyperproliferation and tumor progression and their inhibition by black tea in a 4(methylnitrosamino)-1-(3-pyridyl)-1-butanone-induced lung tumorigenesis model with A/J mice. Cancer research 1997, 57, 1889-1894, https://doi.org/10.1207/s15327914nc4801_7.

202. Chen, J. The effects of Chinese tea on the occurrence of esophageal tumors induced by $\mathrm{N}$ nitrosomethylbenzylamine in rats. Preventive medicine 1992, 21, 385-391, https://doi.org/10.1016/00917435(92)90046-k.

203. Stich, H.F. Teas and tea components as inhibitors of carcinogen formation in model systems and man. Preventive Medicine 1992, 21, 377-384, https://doi.org/10.1016/0091-7435(92)90045-j.

204. Lee, W.J.; Zhu, B.T. Inhibition of DNA methylation by caffeic acid and chlorogenic acid, two common catechol-containing coffee polyphenols. Carcinogenesis 2005, 27, 269-277, https://doi.org/10.1093/carcin/bgi206.

205. Xiang, D.; Wang, D.; He, Y.; Xie, J.; Zhong, Z.; Li, Z.; Xie, J. Caffeic acid phenethyl ester induces growth arrest and apoptosis of colon cancer cells via the $\beta$-catenin/T-cell factor signaling. Anti-cancer drugs 2006, 17, 753-762, https://doi.org/10.1097/01.cad.0000224441.01082.bb.

206. Chen, M.F.; Wu, C.T.; Chen, Y.J.; Keng, P.C.; Chen, W.C. Cell killing and radiosensitization by caffeic acid phenethyl ester (CAPE) in lung cancer cells. Journal of radiation research 2004, 45, 253-260, https://doi.org/10.1269/jrr.45.253.

207. Kudugunti, S.K.; Vad, N.M.; Ekogbo, E.; Moridani, M.Y. Efficacy of caffeic acid phenethyl ester (CAPE) in skin B16-F0 melanoma tumor bearing C57BL/6 mice. Investigational new drugs 2011, 29, 52-62, https://doi.org/10.1007/s10637-009-9334-5.

208. Kuo, H.C.; Kuo, W.H.; Lee, Y.J.; Lin, W.L.; Chou, F.P.; Tseng, T.H. Inhibitory effect of caffeic acid phenethyl ester on the growth of C6 glioma cells in vitro and in vivo. Cancer letters 2006, 234, 199-208, https://doi.org/10.1016/j.canlet.2005.03.046. 
209. Chen, M.J.; Chang, W.H.; Lin, C.C.; Liu, C.Y.; Wang, T.E.; Chu, C.H.; Shih, S.C.; Chen, Y.J. Caffeic acid phenethyl ester induces apoptosis of human pancreatic cancer cells involving caspase and mitochondrial dysfunction. Pancreatology 2008, 8, 566-576..

210. Wu, C.S.; Chen, M.F.; Lee, I.L.; Tung, S.Y. Predictive role of nuclear factor- $\kappa$ B activity in gastric cancer: A promising adjuvant approach with caffeic acid phenethyl ester. Journal of clinical gastroenterology 2007, 41, 894-900, https://doi.org/10.1097/MCG.0b013e31804c707c.

211. Onori, P.; DeMorrow, S.; Gaudio, E.; Franchitto, A.; Mancinelli, R.; Venter, J.; Kopriva, S.; Ueno, Y.; Alvaro, D.; Savage, J. Caffeic acid phenethyl ester decreases cholangiocarcinoma growth by inhibition of $\mathrm{NF}-\mathrm{KB}$ and induction of apoptosis. International journal of cancer 2009, 125, 565-576, https://doi.org/10.1002/ijc.24271.

212. Lee, K.W.; Kang, N.J.; Kim, J.H.; Lee, K.M.; Lee, D.E.; Hur, H.J.; Lee, H.J. Caffeic acid phenethyl ester inhibits invasion and expression of matrix metalloproteinase in SK-Hep1 human hepatocellular carcinoma cells by targeting nuclear factor kappa B. Genes \& nutrition 2008, 2, https://doi.org/10.1007/s12263-0070067-9.

213. Traka, M.; Gasper, A.V.; Smith, J.A.; Hawkey, C.J.; Bao, Y.; Mithen, R.F. Transcriptome analysis of human colon Caco-2 cells exposed to sulforaphane. The Journal of nutrition 2005, 135, 1865-1872, https://doi.org/10.1093/jn/135.8.1865.

214. Wang, L.; Beklemisheva, A.; Liu, X.; Ferrari, A.; Feng, J.; Chiao, J. Dual action on promoter demethylation and chromatin by an isothiocyanate restored GSTP1 silenced in prostate cancer. Molecular Carcinogenesis: Published in cooperation with the University of Texas MD Anderson Cancer Center 2007, 46, 24-31, https://doi.org/10.1002/mc.20258.

215. Wilkinson, J.T.; Morse, M.A.; Kresty, L.A.; Stoner, G.D. Effect of alkyl chain length on inhibition of Nnitrosomethylbenzylamine-induced esophageal tumorigenesis and DNA methylation by isothiocyanates. Carcinogenesis 1995, 16, 1011-1015, https://doi.org/10.1093/carcin/16.5.1011.

216. Kunnumakkara, A.B.; Anand, P.; Aggarwal, B.B. Curcumin inhibits proliferation, invasion, angiogenesis and metastasis of different cancers through interaction with multiple cell signaling proteins. Cancer letters 2008, 269, 199-225, https://doi.org/10.1016/j.canlet.2008.03.009.

217. Anand, P.; Kunnumakkara, A.B.; Newman, R.A.; Aggarwal, B.B. Bioavailability of curcumin: problems and promises. Molecular pharmaceutics 2007, 4, 807-818, https://doi.org/10.1021/mp700113r.

218. Wang, D.; Veena, M.S.; Stevenson, K.; Tang, C.; Ho, B.; Suh, J.D.; Duarte, V.M.; Faull, K.F.; Mehta, K.; Srivatsan, E.S. Liposome-encapsulated curcumin suppresses growth of head and neck squamous cell carcinoma in vitro and in xenografts through the inhibition of nuclear factor $\kappa \mathrm{B}$ by an AKT-independent pathway. Clinical Cancer Research 2008, 14, 6228-6236, https://doi.org/10.1158/1078-0432.CCR-07-5177.

219. Paluszczak, J.; Krajka-Kuźniak, V.; Baer-Dubowska, W. The effect of dietary polyphenols on the epigenetic regulation of gene expression in MCF7 breast cancer cells. Toxicology letters 2010, 192, 119-125, https://doi.org/10.1016/j.toxlet.2009.10.010.

220. Stefanska, B.; Rudnicka, K.; Bednarek, A.; Fabianowska-Majewska, K. Hypomethylation and induction of retinoic acid receptor beta 2 by concurrent action of adenosine analogues and natural compounds in breast cancer cells. European journal of pharmacology 2010, 638, 47-53, https://doi.org/10.1016/j.ejphar.2010.04.032.

221. Gershenzon, J.; Dudareva, N. The function of terpene natural products in the natural world. Nature chemical biology 2007, 3, https://doi.org/10.1038/nchembio.2007.5.

222. Ravichandran, C.; Badgujar, P.C.; Gundev, P.; Upadhyay, A. Review of toxicological assessment of dlimonene, a food and cosmetics additive. Food and chemical toxicology : an international journal published for the British Industrial Biological Research Association 2018, 120, 668-680, https://doi.org/10.1016/j.fct.2018.07.052.

223. Rabi, T.; Bishayee, A. d-Limonene sensitizes docetaxel-induced cytotoxicity in human prostate cancer cells: Generation of reactive oxygen species and induction of apoptosis. Journal of carcinogenesis 2009, 8, https://doi.org/10.4103/1477-3163.51368.

224. Lozon, Y.; Sultan, A.; Lansdell, S.J.; Prytkova, T.; Sadek, B.; Yang, K.H.; Howarth, F.C.; Millar, N.S.; Oz, M. Inhibition of human $\alpha 7$ nicotinic acetylcholine receptors by cyclic monoterpene carveol. Eur J Pharmacol 2016, 776, 44-51, https://doi.org/10.1016/j.ejphar.2016.02.004.

225. Kawata, S.; Nagase, T.; Yamasaki, E.; Ishiguro, H.; Matsuzawa, Y. Modulation of the mevalonate pathway and cell growth by pravastatin and d-limonene in a human hepatoma cell line (Hep G2). British journal of cancer 1994, 69, https://doi.org/10.1038/bjc.1994.199.

226. Kaji, I.; Tatsuta, M.; Iishi, H.; Baba, M.; Inoue, A.; Kasugai, H. Inhibition by D-limonene of experimental hepatocarcinogenesis in Sprague-Dawley rats does not involve p21ras plasma membrane association. International journal of cancer 2001, 93, 441-444, https://doi.org/10.1002/ijc.1353.

227. Ji, J.; Zhang, L.; Wu, Y.Y.; Zhu, X.Y.; Lv, S.Q.; Sun, X.Z. Induction of apoptosis by d-limonene is mediated by a caspase-dependent mitochondrial death pathway in human leukemia cells. Leukemia \& lymphoma 2006, 47, 2617-2624, http://dx.doi.org/10.1080/00268970600909205. 
228. Liu, D.; Chen, Z. The effects of cantharidin and cantharidin derivates on tumour cells. Anti-Cancer Agents in Medicinal Chemistry (Formerly Current Medicinal Chemistry-Anti-Cancer Agents) 2009, 9, 392-396, https://doi.org/10.2174/1871520610909040392.

229. McCluskey, A.; Bowyer, M.C.; Collins, E.; Sim, A.T.; Sakoff, J.A.; Baldwin, M.L. Anhydride modified cantharidin analogues: synthesis, inhibition of protein phosphatases 1 and $2 \mathrm{~A}$ and anticancer activity. Bioorganic \& medicinal chemistry letters 2000, 10, 1687-1690, https://doi.org/10.1016/s0960894x(00)00323-1.

230. Huan, S.K.H.; Lee, H.H.; Liu, D.Z.; Wu, C.C.; Wang, C.C. Cantharidin-induced cytotoxicity and cyclooxygenase 2 expression in human bladder carcinoma cell line. Toxicology 2006, 223, 136-143, https://doi.org/10.1016/j.tox.2006.03.012.

231. Honkanen, R.E. Cantharidin, another natural toxin that inhibits the activity of serine/threonine protein phosphatases types 1 and 2A. FEBS letters 1993, 330, 283-286, https://doi.org/10.1016/00145793(93)80889-3.

232. Liu, R.; Dong, H.F.; Jiang, M.S. Artemisinin: the gifts from traditional Chinese medicine not only for malaria control but also for schistosomiasis control. Parasitology research 2012, 110, 2071-2074, https://doi.org/10.1007/s00436-011-2707-7.

233. Talman, A.M.; Clain, J.; Duval, R.; Ménard, R.; Ariey, F. Artemisinin Bioactivity and Resistance in Malaria Parasites. Trends in parasitology 2019, 35, 953-963, https://doi.org/10.1016/j.pt.2019.09.005.

234. Hou, J.; Wang, D.; Zhang, R.; Wang, H. Experimental therapy of hepatoma with artemisinin and its derivatives: in vitro and in vivo activity, chemosensitization, and mechanisms of action. Clinical cancer research 2008, 14, 5519-5530, https://doi.org/10.1158/1078-0432.CCR-08-0197.

235. Lu, J.J.; Chen, S.M.; Zhang, X.W.; Ding, J.; Meng, L.H. The anti-cancer activity of dihydroartemisinin is associated with induction of iron-dependent endoplasmic reticulum stress in colorectal carcinoma HCT116 cells. Investigational new drugs 2011, 29, 1276-1283, https://doi.org/10.1007/s10637-010-9481-8.

236. Michaelis, M.; Kleinschmidt, M.C.; Barth, S.; Rothweiler, F.; Geiler, J.; Breitling, R.; Mayer, B.; Deubzer, H.; Witt, O.; Kreuter, J. Anti-cancer effects of artesunate in a panel of chemoresistant neuroblastoma cell lines. Biochemical pharmacology 2010, 79, 130-136, https://doi.org/10.1016/j.bcp.2009.08.013.

237. Lu, J.J.; Chen, S.M.; Ding, J.; Meng, L.H. Characterization of dihydroartemisinin-resistant colon carcinoma HCT116/R cell line. Molecular and cellular biochemistry 2012, 360, 329-337, https://doi.org/10.1007/s11010-011-1072-2.

238. Du, J.H.; Zhang, H.D.; Ma, Z.J.; Ji, K.M. Artesunate induces oncosis-like cell death in vitro and has antitumor activity against pancreatic cancer xenografts in vivo. Cancer chemotherapy and pharmacology 2010, 65, 895-902, https://doi.org/10.1007/s00280-009-1095-5.

239. Zhang, S.; Gerhard, G.S. Heme mediates cytotoxicity from artemisinin and serves as a general antiproliferation target. PloS one 2009, 4, https://doi.org/10.1371/journal.pone.0007472.

240. Efferth, T.; Benakis, A.; Romero, M.R.; Tomicic, M.; Rauh, R.; Steinbach, D.; Häfer, R.; Stamminger, T.; Oesch, F.; Kaina, B. Enhancement of cytotoxicity of artemisinins toward cancer cells by ferrous iron. Free Radical Biology and Medicine 2004, 37, 998-1009, https://doi.org/10.1016/j.freeradbiomed.2004.06.023.

241. Chen, T.; Li, M.; Zhang, R.; Wang, H. Dihydroartemisinin induces apoptosis and sensitizes human ovarian cancer cells to carboplatin therapy. Journal of cellular and molecular medicine 2009, 13, 1358-1370, https://doi.org/10.1111/j.1582-4934.2008.00360.x.

242. Chen, H.; Sun, B.; Wang, S.; Pan, S.; Gao, Y.; Bai, X.; Xue, D. Growth inhibitory effects of dihydroartemisinin on pancreatic cancer cells: involvement of cell cycle arrest and inactivation of nuclear factor- $\mathrm{\kappa B}$. Journal of cancer research and clinical oncology 2010, 136, 897-903, https://doi.org/10.1007/s00432-009-0731-0.

243. Willoughby, J.A.; Sundar, S.N.; Cheung, M.; Tin, A.S.; Modiano, J.; Firestone, G.L. Artemisinin blocks prostate cancer growth and cell cycle progression by disrupting $\mathrm{Sp} 1$ interactions with the cyclin-dependent kinase-4 (CDK4) promoter and inhibiting CDK4 gene expression. Journal of Biological Chemistry 2009, 284, 2203-2213, https://doi.org/10.1074/jbc.M804491200.

244. Handrick, R.; Ontikatze, T.; Bauer, K.D.; Freier, F.; Rübel, A.; Dürig, J.; Belka, C.; Jendrossek, V. Dihydroartemisinin induces apoptosis by a Bak-dependent intrinsic pathway. Molecular cancer therapeutics 2010, 1535-7163, https://doi.org/10.1158/1535-7163.MCT-10-0051.

245. Hwang, Y.P.; Yun, H.J.; Kim, H.G.; Han, E.H.; Lee, G.W.; Jeong, H.G. Suppression of PMA-induced tumor cell invasion by dihydroartemisinin via inhibition of PKC $\alpha /$ Raf/MAPKs and NF- $\mathrm{KB} / \mathrm{AP}-1$-dependent mechanisms. Biochemical pharmacology 2010, 79, 1714-1726, https://doi.org/10.1016/j.bcp.2010.02.003.

246. Zhou, L.; Zuo, Z.; Chow, M.S.S. Danshen: an overview of its chemistry, pharmacology, pharmacokinetics, and clinical use. The Journal of Clinical Pharmacology 2005, 45, 1345-1359, https://doi.org/10.1177/0091270005282630.

247. Su, C.C.; Chen, G.W.; Kang, J.C.; Chan, M.H. Growth inhibition and apoptosis induction by tanshinone IIA in human colon adenocarcinoma cells. Planta medica 2008, 74, 1357-1362, https://doi.org/10.1055/s-20081081299.

248. Lee, D.H.; Iwanski, G.B.; Thoennissen, N.H. Cucurbitacin: ancient compound shedding new light on cancer treatment. The Scientific World Journal 2010, 10, 413-418, https://doi.org/10.1100/tsw.2010.44. 
249. Wang, J.; Wang, X.; Jiang, S.; Yuan, S.; Lin, P.; Zhang, J.; Lu, Y.; Wang, Q.; Xiong, Z.; Wu, Y. Growth inhibition and induction of apoptosis and differentiation of tanshinone IIA in human glioma cells. Journal of Neuro-oncology 2007, 82, 11-21, https://doi.org/10.1007/s11060-006-9242-x.

250. Zhang, K.; Li, J.; Meng, W.; Xing, H.; Yang, Y. C/EBP $\beta$ and CHOP participate in tanshinone IIA-induced differentiation and apoptosis of acute promyelocytic leukemia cells in vitro. International journal of hematology 2010, 92, 571-578, https://doi.org/10.1007/s12185-010-0686-6.

251. Yuxian, X.; Feng, T.; Ren, L.; Zhengcai, L. Tanshinone II-A inhibits invasion and metastasis of human hepatocellular carcinoma cells in vitro and in vivo. Tumori Journal 2009, 95, 789-795, https://doi.org/10.1177/030089160909500623.

252. Liu, Q. Triptolide and its expanding multiple pharmacological functions. International immunopharmacology 2011, 11, 377-383, https://doi.org/10.1016/j.intimp.2011.01.012.

253. Qiu, D.; Zhao, G.; Aoki, Y.; Shi, L.; Uyei, A.; Nazarian, S.; Ng, J.C.H.; Kao, P.N. Immunosuppressant PG490 (triptolide) inhibits T-cell interleukin-2 expression at the level of purine-box/nuclear factor of activated T-cells and NF- $\mathrm{B}$ transcriptional activation. Journal of biological chemistry 1999, 274, 1344313450, https://doi.org/10.1074/jbc.274.19.13443.

254. Westerheide, S.D.; Kawahara, T.L.; Orton, K.; Morimoto, R.I. Triptolide, an inhibitor of the human heat shock response that enhances stress-induced cell death. Journal of biological chemistry 2006, https://doi.org/10.1074/jbc.M512044200.

255. Wang, Y.; Lu, J.J.; He, L.; Yu, Q. Triptolide (TPL) inhibits global transcription by inducing proteasomedependent degradation of RNA polymerase II (Pol II). PLoS One 2011, 6, https://doi.org/10.1371/journal.pone.0023993.

256. Leuenroth, S.J.; Okuhara, D.; Shotwell, J.D.; Markowitz, G.S.; Yu, Z.; Somlo, S.; Crews, C.M. Triptolide is a traditional Chinese medicine-derived inhibitor of polycystic kidney disease. Proceedings of the National Academy of Sciences 2007, 104, 4389-4394, https://doi.org/10.1073/pnas.0700499104.

257. McCallum, C.; Kwon, S.; Leavitt, P.; Shen, D.M.; Liu, W.; Gurnett, A. Triptolide binds covalently to a 90 $\mathrm{kDa}$ nuclear protein. Role of epoxides in binding and activity. Immunobiology 2007, 212, 549-556, https://doi.org/10.1016/j.imbio.2007.02.002.

258. Titov, D.V.; Gilman, B.; He, Q.L.; Bhat, S.; Low, W.K.; Dang, Y.; Smeaton, M.; Demain, A.L.; Miller, P.S.; Kugel, J.F. XPB, a subunit of TFIIH, is a target of the natural product triptolide. Nature chemical biology 2011, 7, https://doi.org/10.1038/nchembio.522.

259. Lim, J.C.W.; Chan, T.K.; Ng, D.S.; Sagineedu, S.R.; Stanslas, J.; Wong, W.F. Andrographolide and its analogues: versatile bioactive molecules for combating inflammation and cancer. Clinical and Experimental Pharmacology and Physiology 2012, 39, 300-310, https://doi.org/10.1111/j.1440-1681.2011.05633.x.

260. Dai, Y.; Chen, S.R.; Chai, L.; Zhao, J.; Wang, Y.; Wang, Y. Overview of pharmacological activities of Andrographis paniculata and its major compound andrographolide. Critical reviews in food science and nutrition 2019, 59, S17-S29, https://doi.org/10.1080/10408398.2018.1501657.

261. Yu, B.C.; Chen, W.C.; Cheng, J.T. Antihyperglycemic effect of andrographolide in streptozotocin-induced diabetic rats. Planta medica 2003, 69, 1075-1079, https://doi.org/10.1055/s-2003-45185.

262. Xia, Y.F.; Ye, B.Q.; Li, Y.D.; Wang, J.G.; He, X.J.; Lin, X.; Yao, X.; Ma, D.; Slungaard, A.; Hebbel, R.P. Andrographolide attenuates inflammation by inhibition of NF- $\kappa$ B activation through covalent modification of reduced cysteine 62 of p50. The Journal of Immunology 2004, 173, 4207-4217, https://doi.org/10.4049/jimmunol.173.6.4207.

263. Wang, L.J.; Zhou, X.; Wang, W.; Tang, F.; Qi, C.L.; Yang, X.; Wu, S.; Lin, Y.Q.; Wang, J.T.; Geng, J.G. Andrographolide inhibits oral squamous cell carcinogenesis through NF- $\kappa$ B inactivation. Journal of dental research 2011, 90, 1246-1252, https://doi.org/10.1177/0022034511418341.

264. Ikezoe, T.; Yang, Y.; Bandobashi, K.; Saito, T.; Takemoto, S.; Machida, H.; Togitani, K.; Koeffler, H.P.; Taguchi, H. Oridonin, a diterpenoid purified from Rabdosia rubescens, inhibits the proliferation of cells from

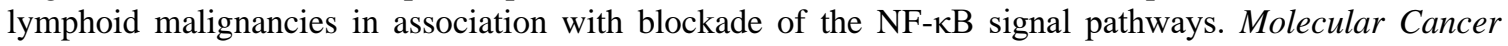
Therapeutics 2005, 4, 578-586, https://doi.org/10.1158/1535-7163.MCT-04-0277.

265. Jin, H.; Tan, X.; Liu, X.; Ding, Y. Downregulation of AP-1 gene expression is an initial event in the oridoninmediated inhibition of colorectal cancer: Studies in vitro and in vivo. Journal of gastroenterology and hepatology 2011, 26, 706-715, https://doi.org/10.1111/j.1440-1746.2010.06500.x.

266. Hu, H.Z.; Yang, Y.B.; Xu, X.D.; Shen, H.W.; Shu, Y.M.; Ren, Z.; Li, X.M.; Shen, H.M.; Zeng, H.T. Oridonin induces apoptosis via PI3K/Akt pathway in cervical carcinoma HeLa cell line. Acta Pharmacologica Sinica 2007, 28, 1819-1826, https://doi.org/10.1111/j.1745-7254.2007.00667.x.

267. Zhang, Y.; Wu, Y.; Wu, D.; Tashiro, S.I.; Onodera, S.; Ikejima, T. NF-кB facilitates oridonin-induced apoptosis and autophagy in HT1080 cells through a p53-mediated pathway. Archives of biochemistry and biophysics 2009, 489, 25-33, https://doi.org/10.1016/j.abb.2009.07.017.

268. Cheng, Y.; Qiu, F.; Ikejima, T. Molecular mechanisms of oridonin-induced apoptosis and autophagy in murine fibrosarcoma L929 cells. Autophagy 2009, 5, 430-431, https://doi.org/10.4161/auto.5.3.7896.

269. Cheng, Y.; Qiu, F.; Ye, Y.C.; Guo, Z.M.; Tashiro, S.I.; Onodera, S.; Ikejima, T. Autophagy inhibits reactive oxygen species-mediated apoptosis via activating p38-nuclear factor-kappa B survival pathways in oridonin- 
treated murine fibrosarcoma L929 cells. The FEBS journal 2009, 276, 1291-1306, https://doi.org/10.1111/j.1742-4658.2008.06864.x.

270. Zhang, Y.H.; Wu, Y.L.; Tashiro, S.I.; Onodera, S.; Ikejima, T. Reactive oxygen species contribute to oridonin-induced apoptosis and autophagy in human cervical carcinoma HeLa cells. Acta Pharmacologica Sinica 2011, 32, 1266, https://doi.org/10.1038/aps.2011.92.

271. Calixto, J.B.; Otuki, M.F.; Santos, A.R. Anti-inflammatory compounds of plant origin. Part I. Action on arachidonic acid pathway, nitric oxide and nuclear factor $\kappa$ B (NF-кB). Planta medica 2003, 69, 973-983, https://doi.org/10.1055/s-2003-45141.

272. Li, H.; Zhang, Y.Y.; Huang, X.Y.; Sun, Y.N.; Jia, Y.F.; Li, D. Beneficial effect of tripterine on systemic lupus erythematosus induced by active chromatin in BALB/c mice. European journal of pharmacology 2005, 512, 231-237, https://doi.org/10.1016/j.ejphar.2005.02.030.

273. Zhang, D.H.; Marconi, A.; Xu, L.M.; Yang, C.X.; Sun, G.W.; Feng, X.L.; Ling, C.Q.; Qin, W.Z.; Uzan, G.; d'Alessio, P. Tripterine inhibits the expression of adhesion molecules in activated endothelial cells. Journal of leukocyte biology 2006, 80, 309-319, https://doi.org/10.1189/jlb.1005611.

274. Yu, X.; Tao, W.; Jiang, F.; Li, C.; Lin, J.; Liu, C. Celastrol attenuates hypertension-induced inflammation and oxidative stress in vascular smooth muscle cells via induction of heme oxygenase-1. American journal of hypertension 2010, 23, 895-903, https://doi.org/10.1038/ajh.2010.75.

275. Chambliss, O.L.; Jones, C.M. Cucurbitacins: specific insect attractants in Cucurbitaceae. Science 1966, 153 , 1392-1393, https://doi.org/10.1126/science.153.3742.1392.

276. Chan, K.T.; Meng, F.Y.; Li, Q.; Ho, C.Y.; Lam, T.S.; To, Y.; Lee, W.H.; Li, M.; Chu, K.H.; Toh, M. Cucurbitacin B induces apoptosis and S phase cell cycle arrest in BEL-7402 human hepatocellular carcinoma cells and is effective via oral administration. Cancer letters 2010, 294, 118-124, https://doi.org/10.1016/j.canlet.2010.01.029.

277. Hsu, H.S.; Huang, P.I.; Chang, Y.L.; Tzao, C.; Chen, Y.W.; Shih, H.C.; Hung, S.C.; Chen, Y.C.; Tseng, L.M.; Chiou, S.H. Cucurbitacin I inhibits tumorigenic ability and enhances radiochemosensitivity in nonsmall cell lung cancer-derived CD133-positive cells. Cancer 2011, 117, 2970-2985, https://doi.org/10.1002/cncr.25869.

278. Ouyang, D.; Zhang, Y.; Xu, L.; Li, J.; Zha, Q.; He, X. Histone deacetylase inhibitor valproic acid sensitizes B16F10 melanoma cells to cucurbitacin B treatment. Acta Biochim Biophys Sin 2011, 43, 487-495, https://doi.org/10.1093/abbs/gmr032.

279. Chen, Y.W.; Chen, K.H.; Huang, P.I.; Chen, Y.C.; Chiou, G.Y.; Lo, W.L.; Tseng, L.M.; Hsu, H.S.; Chang, K.W.; Chiou, S.H. Cucurbitacin I suppressed stem-like property and enhanced radiation-induced apoptosis in head and neck squamous carcinoma-derived CD44+ ALDH1+ cells. Molecular cancer therapeutics 2010, 1535-7163, https://doi.org/10.1158/1535-7163.MCT-10-0504.

280. Cheng, L.; Xu, P.H.; Shen, B.D.; Shen, G.; Li, J.J.; Qiu, L.; Liu, C.Y.; Yuan, H.L.; Han, J. Improve bile duct-targeted drug delivery and therapeutic efficacy for cholangiocarcinoma by cucurbitacin B loaded phospholipid complex modified with berberine hydrochloride. International journal of pharmaceutics $\mathbf{2 0 1 5}$, 489, 148-157, https://doi.org/10.1016/j.ijpharm.2015.04.024.

281. Thoennissen, N.H.; Iwanski, G.B.; Doan, N.B.; Okamoto, R.; Lin, P.; Abbassi, S.; Song, J.H.; Yin, D.; Toh, M.; Xie, W.D. Cucurbitacin B induces apoptosis by inhibition of the JAK/STAT pathway and potentiates antiproliferative effects of gemcitabine on pancreatic cancer cells. Cancer research 2009, 69, 5876-5884, https://doi.org/10.1158/0008-5472.CAN-09-0536.

282. Liu, T.; Zhang, M.; Zhang, H.; Sun, C.; Yang, X.; Deng, Y.; Ji, W. Combined antitumor activity of cucurbitacin B and docetaxel in laryngeal cancer. European journal of pharmacology 2008, 587, 78-84, https://doi.org/10.1016/j.ejphar.2008.03.032.

283. Cao, J.X.; Zhang, Q.Y.; Cui, S.Y.; Cui, X.Y.; Zhang, J.; Zhang, Y.H.; Bai, Y.J.; Zhao, Y.Y. Hypnotic effect of jujubosides from Semen Ziziphi Spinosae. Journal of ethnopharmacology 2010, 130, 163-166, https://doi.org/10.1016/j.jep.2010.03.023.

284. Qian, Z.K.; Cui, F.; Ling, Y.X.; Zhu, W.J.; Li, X.Q.; Mao, Z.; Li, M.T. Alisma orientalis (Sam.) juzep polysaccharide-regulated glucose-lipid metabolism in experimental rats and cell model of diabetes mellitus with regulation of miR-126. Pharmacognosy Magazine 2019, 15, https://doi.org/10.4103/pm.pm_441_18.

285. Ray, A.B.; Bala, K. Bioactive Compounds and Health Benefits of Phalsa: An Underutilized Fruit. Food Bioactives: Functionality and Applications in Human Health 2019, 109, https://doi.org/10.1201/9780429242793-5.

286. Lee, S.; Kho, Y.; Min, B.; Kim, J.; Na, M.; Kang, S.; Maeng, H.; Bae, K. Cytotoxic triterpenoides from Alismatis rhizoma. Archives of pharmacal research 2001, 24, 524-526, https://doi.org/10.1007/BF02975158.

287. Law, B.Y.; Wang, M.; Ma, D.L.; Al-Mousa, F.; Michelangeli, F.; Cheng, S.H.; Ng, M.H.; To, K.F.; Mok, A.Y.; Ko, R.Y. Alisol B, a novel inhibitor of the sarcoplasmic/endoplasmic reticulum Ca2+ ATPase pump, induces autophagy, endoplasmic reticulum stress, and apoptosis. Molecular cancer therapeutics 2010, 15357163, https://doi.org/10.1158/1535-7163.MCT-09-0700. 
288. Chou, C.; Pan, S.; Teng, C.; Guh, J. Pharmacological evaluation of several major ingredients of Chinese herbal medicines in human hepatoma Hep3B cells. European Journal of Pharmaceutical Sciences 2003, 19, 403-412, https://doi.org/10.1016/s0928-0987(03)00144-1.

289. Wang, C.; Zhang, J.X.; Shen, X.L.; Wan, C.K.; Tse, A.K.W.; Fong, W.F. Reversal of P-glycoproteinmediated multidrug resistance by Alisol B 23-acetate. Biochemical pharmacology 2004, 68, 843-855, https://doi.org/10.1016/j.bcp.2004.05.021.

290. Prieto, J.; Recio, M.; Giner, R.M.; Manez, S.; Giner-Larza, E.; Rios, J. Influence of traditional Chinese antiinflammatory medicinal plants on leukocyte and platelet functions. Journal of Pharmacy and Pharmacology 2003, 55, 1275-1282, https://doi.org/10.1211/0022357021620.

291. Ling, H.; Zhang, Y.; Ng, K.Y.; Chew, E.H. Pachymic acid impairs breast cancer cell invasion by suppressing nuclear factor- $\mathrm{\kappa B}$-dependent matrix metalloproteinase-9 expression. Breast cancer research and treatment 2011, 126, 609-620, https://doi.org/10.1007/s10549-010-0929-5.

292. Jin, J.; Zhou, R.; Xie, J.; Ye, H.; Liang, X.; Zhong, C.; Shen, B.; Qin, Y.; Zhang, S.; Huang, L. Insights into triterpene acids in fermented mycelia of edible fungus Poria cocos by a comparative study. Molecules 2019 , 24, https://doi.org/10.3390/molecules24071331.

293. Zhou, L.; Zhang, Y.; Gapter, L.A.; Ling, H.; Agarwal, R.; Ng, K.Y. Cytotoxic and anti-oxidant activities of lanostane-type triterpenes isolated from Poria cocos. Chemical and Pharmaceutical Bulletin 2008, 56, 14591462, https://doi.org/10.1248/cpb.56.1459.

294. Gapter, L.; Wang, Z.; Glinski, J.; Ng, K.Y. Induction of apoptosis in prostate cancer cells by pachymic acid from Poria cocos. Biochemical and biophysical research communications 2005, 332, 1153-1161, https://doi.org/10.1016/j.bbrc.2005.05.044.

295. Li, G.; Xu, M.L.; Lee, C.S.; Woo, M.H.; Chang, H.W.; Son, J.K. Cytotoxicity and dna topoisomerases inhibitory activity of constituents from the sclerotium ofPoria cocos. Archives of pharmacal research 2004, 27, https://doi.org/10.1007/BF02980174.

296. Ling, H.; Jia, X.; Zhang, Y.; Gapter, L.A.; Lim, Y.S.; Agarwal, R.; Ng, K.Y. Pachymic acid inhibits cell growth and modulates arachidonic acid metabolism in nonsmall cell lung cancer A549 cells. Molecular Carcinogenesis: Published in cooperation with the University of Texas MD Anderson Cancer Center 2010, 49, 271-282, https://doi.org/10.1002/mc.20597.

297. Han, C.; Kawata, M.; Hamada, Y.; Kondo, T.; Wada, J.; Asano, K.; Makabe, H.; Igarashi, K.; Kuzumaki, N.; Narita, M. Analyses of the possible anti-tumor effect of yokukansan. Journal of natural medicines 2019, 73, 468-479, https://doi.org/10.1007/s11418-019-01283-х.

298. Tapiero, H.; Townsend, D.; Tew, K. The role of carotenoids in the prevention of human pathologies. Biomedicine \& Pharmacotherapy 2004, 58, 100-110, https://doi.org/10.1016/j.biopha.2003.12.006.

299. Andersen, T.; Rodríguez-Concepción, M. Diversifying biosynthesis and storage capacity of carotenoids in plants. 2019.

300. Wei, W.J.; Song, Q.Y.; Ying, J.C.; Li, H.Y.; Ma, K.L.; Li, Y.; Li, Y.; Gao, K. Highly Oxygenated Triterpenoids and Rare Tetraterpenoids from Abies chensiensis and Their Antibacterial Activity. Journal of natural products 2019, 82, 2859-2869, https://doi.org/10.1021/acs.jnatprod.9b00616.

301. Tanaka, T.; Shnimizu, M.; Moriwaki, H. Cancer chemoprevention by carotenoids. Molecules 2012, 17, 3202-3242, https://doi.org/10.3390/molecules17033202.

302. Sen, S. The Chemistry and Biology of Lycopene: Antioxidant for Human Health. Int J Adv Life Sci Res 2019, 2, 08-14, https://doi.org/10.31632/ijalsr.2019v02i04.002.

303. Ma, Y.R.; Wang, K.F.; Wang, W.J.; Ding, Y.; Shi, T.Q.; Huang, H.; Ji, X.J. Advances in the metabolic engineering of Yarrowia lipolytica for the production of terpenoids. Bioresource technology 2019, 281, 449456, https://doi.org/10.1016/j.biortech.2019.02.116.

304. Vaishampayan, U.; Hussain, M.; Banerjee, M.; Seren, S.; Sarkar, F.H.; Fontana, J.; Forman, J.D.; Cher, M.L.; Powell, I.; Pontes, J.E. Lycopene and soy isoflavones in the treatment of prostate cancer. Nutrition and cancer 2007, 59, 1-7, https://doi.org/10.1080/01635580701413934.

305. Kelkel, M.; Schumacher, M.; Dicato, M.; Diederich, M. Antioxidant and anti-proliferative properties of lycopene. Free radical research 2011, 45, 925-940, https://doi.org/10.3109/10715762.2011.564168.

306. Uppala, P.T.; Dissmore, T.; Lau, B.H.; Andacht, T.; Rajaram, S. Selective Inhibition of Cell Proliferation by Lycopene in MCF-7 Breast Cancer Cells In vitro: A Proteomic Analysis. Phytotherapy Research 2013, 27, 595-601, https://doi.org/10.1002/ptr.4764. 